\title{
Design and Operation of a Sensible Heat Peaking Unit for Small Modular Reactors
}

Konor Frick, Joseph Michael Doster, Shannon Bragg-Sitton

August 2018

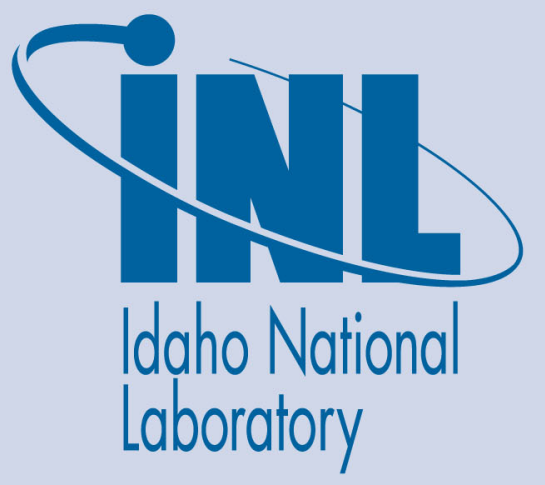

The INL is a U.S. Department of Energy National Laboratory operated by Battelle Energy Alliance 


\title{
Design and Operation of a Sensible Heat Peaking Unit for Small Modular Reactors
}

\author{
Konor Frick, Joseph Michael Doster, Shannon Bragg-Sitton
}

\author{
August 2018 \\ Idaho National Laboratory \\ Idaho Falls, Idaho 83415 \\ http://www.inl.gov \\ Prepared for the \\ U.S. Department of Energy \\ Under DOE Idaho Operations Office \\ Contract DE-AC07-05ID14517
}


Title: Design and Operation of a Sensible Heat Peaking Unit for Small Modular Reactors

Article Type: Original Research Paper

Authors: Konor Frick ${ }^{\mathrm{a} *}$, Dr. J. Michael Doster ${ }^{\mathrm{a}}$, Dr. Shannon Bragg-Sitton ${ }^{\mathrm{b}}$

a'Department of Nuclear Engineering, North Carolina State University, 2500 Stinson Drive, 3105

Burlington Engineering Labs, Raleigh, NC, 27695-7909

${ }^{\mathrm{b}}$ Systems Integration Department, Idaho National Laboratory

*Corresponding Author, Email: klfrick2@ncsu.edu, Phone: 919.270.2791

Total number of Pages : 47

Total number of Tables : 3

Total number of Figures : 69

Send proofs and page charge invoice to: Konor Frick

email: klfrick2@ncsu.edu

Address: Department of Nuclear Engineering, North Carolina State University, 2500 Stinson Drive, 3105 Burlington Engineering Labs, Raleigh, NC, 27695-7909 


\begin{abstract}
Approximately $19 \%$ of the electricity produced in the United States comes from nuclear power plants. Traditionally, nuclear power plants, as well as larger coal-fired plants, operate in a baseload manner at or near steady-state for prolonged periods of time. Smaller, more maneuverable plants, such as gas-fired plants, are dispatched to match electricity supply and demand above the capacity of the baseload plants. However, air quality concerns and $\mathrm{CO}_{2}$ emission standards has made the burning of fossil fuels less desirable, despite the current low cost of natural gas. Wind and solar photovoltaic (PV) power generation are attractive options due to their lack of carbon footprint and falling capital costs. Yet, these renewable energy sources suffer from inherent intermittency. This inherent intermittency can strain electric grids, forcing carbon-based and nuclear sources of energy to operate in a load follow mode. For nuclear reactors, load follow operation can be undesirable due to the associated thermal and mechanical stresses placed on the fuel and other reactor components. Various methods of Thermal Energy Storage (TES) can be coupled to nuclear (or renewable) power sources to help absorb grid variability caused by daily load demand changes and renewable intermittency. Our previous research has shown that coupling a sensible heat TES system to a Small Modular Reactor (SMR) allows the reactor to run at effectively nominal full power during periods of variable electric demand by bypassing steam to the TES system during periods of excess capacity. In this paper we demonstrate that this stored thermal energy can be recovered, allowing the TES system to act as a peaking unit during periods of high electric demand, or used to produce steam for ancillary applications such as desalination. For both applications the reactor is capable of operating continuously at approximately $100 \%$ power.
\end{abstract}

Keywords: Thermal Energy Storage (TES), Small Modular Reactor (SMR), Integral Pressurized Water Reactor (IPWR), Nuclear-Hybrid Energy System (NHES) 


\section{Introduction}

Renewable energy technologies continue to become more attractive with improvements in efficiency and price-point. However, since renewables have grid priority, variability of these generators create additional challenges for the electric grid in the form of rapidly varying net electric loads. This can lead to mismatches between energy demand and energy production and ultimately system instabilities and blackouts. Furthermore, the integration of renewable energy can lead to over-generation potential as shown in Figure 1. This over-generation potential can lead to negative electric prices where the utility is forced to pay customers who are willing to take the power produced. Negative prices occur when a large amount of inflexible power generation occurs simultaneously with low demand [1]. This phenomenon occurs more frequently when a large amount of intermittent renewable energy is introduced to the grid.

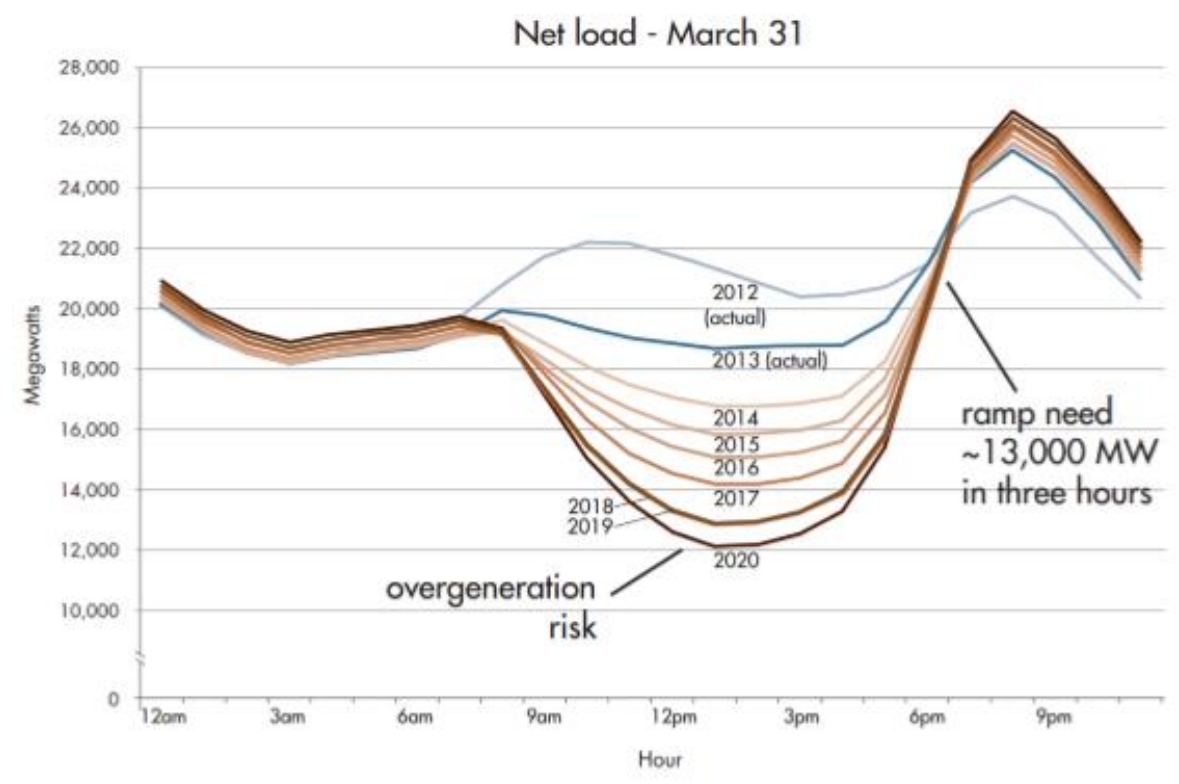

Figure 1: "Duck Curve" from substantial renewable energy (solar PV) integration in California [2]

To maintain our current lifestyle, base load plants will still be required. However, as the penetration of renewables increases, base load plants will need to be more flexible in their operation. Small Modular Reactors (SMRs) can potentially provide this flexibility in operation. SMRs offer increased site compatibility, advanced passive safety systems for the removal of decay heat, lower capital costs for 
construction, and reduced primary and secondary-side inventory [3]. With a nominal electrical output of 300 MWe or less, SMRs can be clustered in a single location to form a more traditional baseload nuclear power plant, or deployed to remote locations, such as military bases with limited grid access, to provide reliable emissions-free energy [4]. During times when the reactor is subjected to significant time varying electric loads there are three options: operate in load follow mode, operate at or near steady state and bypass steam directly to the condenser [5], or maintain power and store the excess energy for later use. The first two options result in lost energy potential. Load follow operation can also result in additional stresses on the fuel and other mechanical components. The more attractive approach is to operate the reactor at or near steady state and bypass excess steam to a thermal energy storage system. The thermal energy can then be recovered, either as a supplement to the power plant during peak demand times, or for process steam applications. This paper examines issues that occur when SMRs are subjected to significant time varying net electric loads and proposes a sensible heat thermal energy storage system to mitigate these issues.

\section{System Design, Connection, and Control}

Integrated nuclear hybrid energy systems (NHES) involve the design and connection of several complex, standalone systems. The control algorithms involved are unique to each application and the particular design of the components. NHES architectures can include process steam applications, energy storage, and the presence of intermittent energy sources such as wind and solar. An example architecture is given in Figure 2. The hybrid energy system described in this paper utilizes an mPower [6] style SMR connected to a two-tank sensible heat thermal energy storage system. 


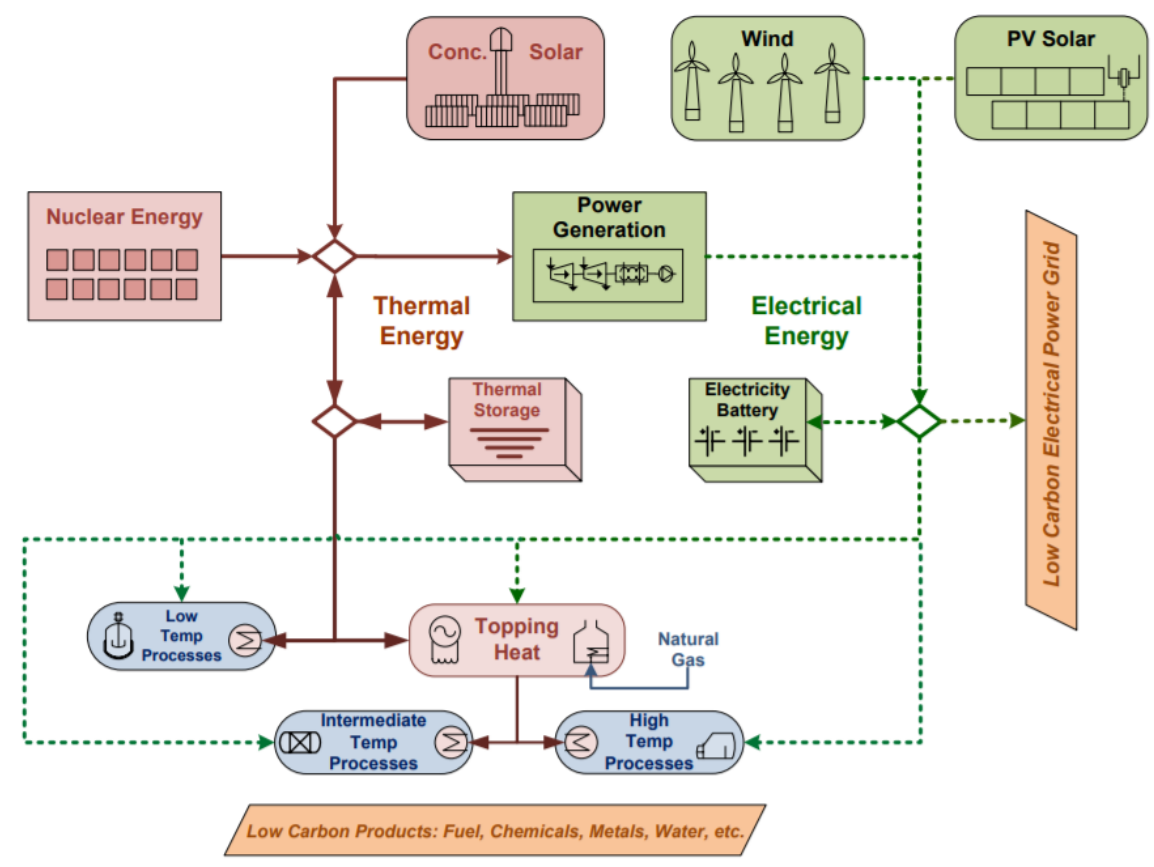

Figure 2: Example architecture for a tightly coupled NHES, proposed by Idaho National Laboratory [7]

\section{II.A. Reactor Simulator}

The target SMR in this work is a representative Integral Pressurized Water Reactor (IPWR) with operating parameters similar to those of the mPower reactor proposed by $\mathrm{B} \& \mathrm{~W}[6]$. Operating parameters are given in Table I. IPWRs are characterized by having all major primary system components (core, steam generators, pressurizer, etc.) contained within the reactor vessel. A diagram of a typical IPWR is given in Figure 3. 


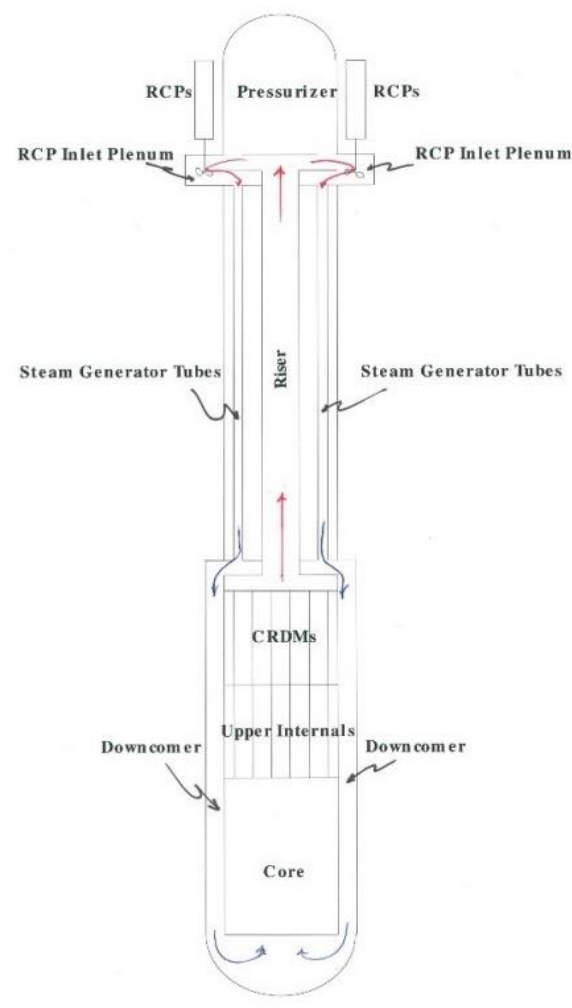

\section{Figure 3: Representative Integral Pressurized Water Reactor}

For the IPWR considered in this work the steam generators are a typical once through design, with steam generator pressure control via the turbine control valves (TCVs) located between the pressure equalization header and the high pressure turbine. Feed control valves modulate such that feed flow rate matches a feed demand signal that is proportional to the turbine load plus a shim that insures turbine output matches load. Steam generator level (boiling length) is allowed to float. In order to simulate the dynamics of an IPWR system, NCSU has developed high fidelity simulation tools for predicting the dynamic response of IPWR systems under normal and off-normal conditions [8-11]. The reactor simulator is capable of simulating IPWRs operating under forced and natural circulation conditions. Additional features include: a) reactor kinetics with overlapping control rod banks, Xenon, fuel and moderator temperature feedback, b) decay heat, c) hot channel models including Critical Heat Flux and peak fuel centerline temperatures, d) pressurizer with heaters and sprays, e) conventional and helical coil Once Through Steam Generators, f) 
Balance of Plant and g) associated control functions. Models exist for IPWR concepts spanning a range of thermal outputs, including designs similar to the Westinghouse IRIS, B\&W, mPower, and NuScale reactor concepts [6].

Table I: SMR Operating Parameters

\begin{tabular}{|l|l|}
\hline Parameter & Value \\
\hline Reactor Thermal Output & $530 \mathrm{MWt}$ \\
\hline Electric Output & $180 \mathrm{MWe}$ \\
\hline Primary System Pressure & $14.134 \mathrm{MPa}(2050 \mathrm{psia})$ \\
\hline Core Inlet Temperature & $297^{\circ} \mathrm{C}\left(566^{\circ} \mathrm{F}\right)$ \\
\hline Core Exit Temperature & $322^{\circ} \mathrm{C}\left(611^{\circ} \mathrm{F}\right)$ \\
\hline Core Flow Rate & $13.6 \times 10^{6} \mathrm{~kg} / \mathrm{hr}(30 \mathrm{Mlbm} / \mathrm{hr})$ \\
\hline Steam Pressure & $5.68 \mathrm{MPa}(825 \mathrm{psia})$ \\
\hline Steam Temperature & $299^{\circ} \mathrm{C}\left(571{ }^{\circ} \mathrm{F}\right)$ \\
\hline Feed Temperature & $212^{\circ} \mathrm{C}\left(414^{\circ} \mathrm{F}\right)$ \\
\hline Steam Flow Rate & $9.53 \times 10^{5} \mathrm{~kg} / \mathrm{hr}(2.1 \mathrm{Mlbm} / \mathrm{hr})$ \\
\hline
\end{tabular}

\section{II.B. Sensible Heat Storage System}

Sensible heat storage involves the heating of a solid or liquid without phase change and can be deconstructed into two operating modes: charging and discharging. A two-tank thermal energy storage system is a common configuration for liquid sensible heat systems. In the charging mode, cold fluid is pumped from a cold tank through an Intermediate Heat Exchanger (IHX), heated, and stored in a hot tank. In the discharge mode, the TES fluid is pumped from the hot tank to some energy recovery process (e.g. a steam generator) and returned to the cold tank. Such systems have been successfully demonstrated in the solar energy field as a load management strategy [12].

\section{II.B.1. Connection Point}

The performance of a Thermal Energy Storage (TES) System is a strong function of the connection point to the secondary side of the IPWR. For plants incorporating Once Through Steam Generators (OTSG) the turbine control valves (TCVs) act as pressure control valves to maintain Steam Generator pressure at a 
given set point. Shown in Figure 4, Turbine Bypass Valves (TBVs) can be configured such that bypass steam can either be taken off the steam line at the pressure equalization header upstream of the turbine control valves (Aux 1), downstream of the turbine control valves prior to entering the high pressure turbine (Aux 2), or at some low pressure turbine tap (Aux 3). Steam off-take upstream of the TCVs provides approximately constant steam conditions, but the system is only able to bypass $\sim 50 \%$ nominal steam flow before losing pressure control. Should more steam flow be desired, then placing the taps downstream of the TCVs is an option that has no steam flow limitation. However, steam conditions downstream of the TCVs are a strong function of the load profile. Taking bypass steam downstream of the turbine control valves can result in highly varying steam pressures and temperatures and unacceptably low IHX pressures. Further, if the TBVs are placed downstream of the TCVs then TBV operation must be uniform to maintain symmetric operation of the TCVs. For the sensible heat TES system assumed here, it is desirable to have roughly constant steam conditions since the shell side pressure in the Intermediate Heat Exchanger directly affects the TES fluid temperature leaving the IHX and ultimately stored in the hot tank. This makes taking bypass steam from the pressure equalization header upstream of the turbine control valves the preferred operating mode. 


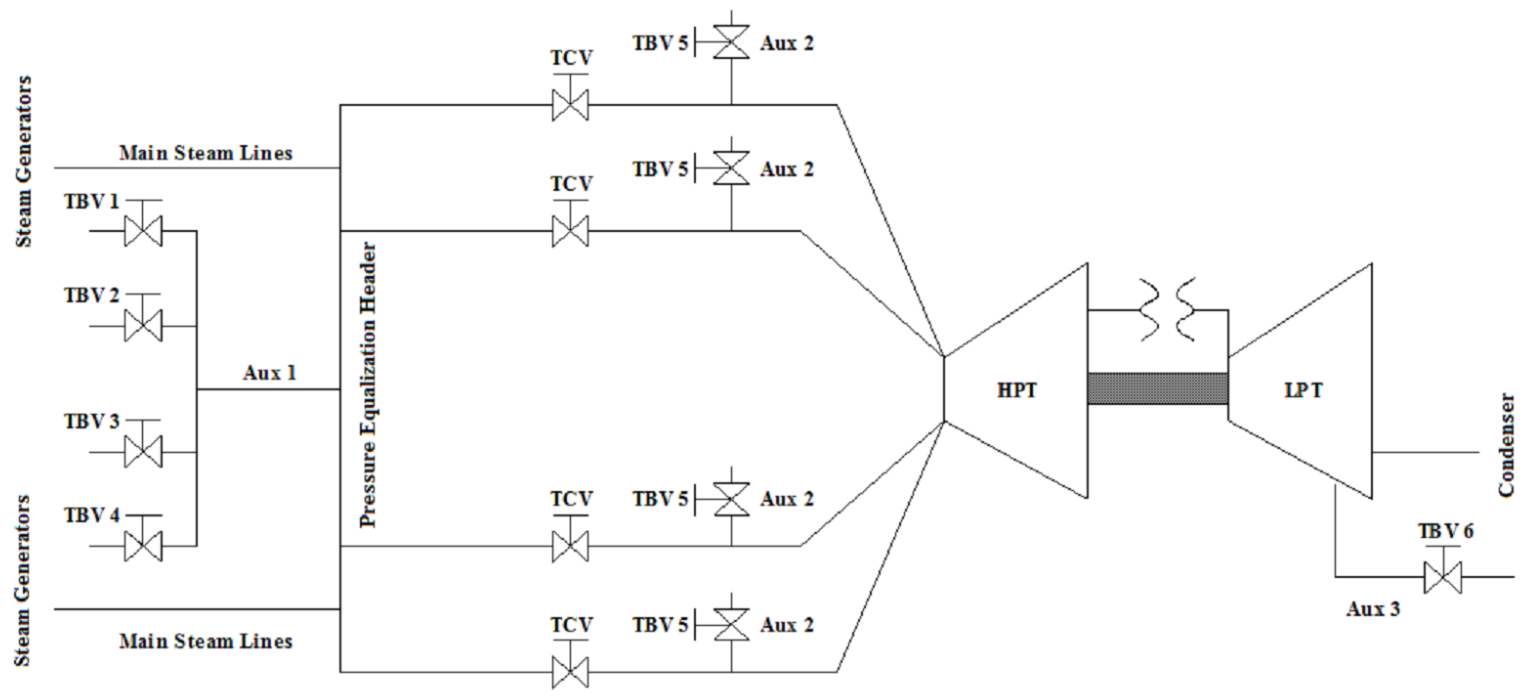

Figure 4: Bypass Steam Options

\section{II.B.2. $\quad$ Charging System Design}

The proposed Thermal Energy Storage System is shown in Figure 5. An outer loop interfaces with the reactor's Balance of Plant (BOP) directly through four parallel auxiliary turbine bypass valves connected at the pressure equalization header, each staged to open at a certain percent of the maximum auxiliary flow demand. Bypass steam is directed through an intermediate heat exchanger (IHX) and discharged to the main condenser or some other low pressure process [13]. An inner loop containing a TES fluid consists of two large storage tanks along with several pumps to transport the TES fluid between the tanks, the IHX and a steam generator. Flow Bypass Valves are included in the discharge lines of both the Hot and Cold tanks to prevent deadheading the pumps when the Flow Control Valves are closed. Common TES fluid properties are given in Table II. While the models are sufficiently general to handle any TES fluid, Therminol-66 is chosen as the TES fluid in this work as it is readily available, can be pumped at low temperatures, and offers thermal stability over the range $-3{ }^{\circ} \mathrm{C}-343^{\circ} \mathrm{C}$, which covers the anticipated operating range of the TES system $\left(203^{\circ} \mathrm{C}-260^{\circ} \mathrm{C}\right)$. Molten salts (e.g. $\left.48 \% \mathrm{NaNO} 3-52 \% \mathrm{KNO} 3\right)$ were 
not considered, as the anticipated operating temperatures fall below their $222{ }^{\circ} \mathrm{C}$ freezing temperature [14]. Other benefits of using Therminol-66 include its Material Safety Data Sheet (MSDS) classification as a nonhazardous material [15]. In addition, as hydrocarbons do not readily exchange hydrogen atoms with other materials [16], tritium migration would be mitigated in the rare event of simultaneous leaks in the steam generator and an IHX tube allowed activated primary water to mix with the TES fluid. In this event, the TES tanks would act as holding tanks for the activated water.

Table II: Properties of Possible TES fluids at 260 degrees Celsius (500 degrees Fahrenheit)

\begin{tabular}{|c|c|c|c|}
\hline Heat Transfer Fluid & Boiling Point $\left({ }^{\circ} \mathrm{C}\right)$ & $\begin{array}{l}\text { Heat Storage } \\
\left(\mathbf{W}^{*} \mathbf{h r} / \mathbf{m}^{3} \circ \mathbf{C}\right)\end{array}$ & Operating Range $\left({ }^{\circ} \mathrm{C}\right)$ \\
\hline Therminol®-66 [17] & $358\left(678^{\circ} \mathrm{F}\right)$ & $1039\left(576.95 \mathrm{~W} * \mathrm{hr} / \mathrm{m}^{3 \circ} \mathrm{F}\right)$ & -2.7 to $343.3\left(27^{\circ} \mathrm{F}\right.$ to $\left.650^{\circ} \mathrm{F}\right)$ \\
\hline Therminol®-68 [18] & $307\left(586^{\circ} \mathrm{F}\right)$ & $1013\left(563.03 \mathrm{~W}^{*} \mathrm{hr} / \mathrm{m}^{3 \circ} \mathrm{F}\right)$ & -25.5 to $360\left(-14^{\circ} \mathrm{F}\right.$ to $\left.680^{\circ} \mathrm{F}\right)$ \\
\hline Therminol@-75 [19] & $342\left(649^{\circ} \mathrm{F}\right)$ & $992\left(551.54 \mathrm{~W}^{*} \mathrm{hr} / \mathrm{m}^{3 \circ} \mathrm{F}\right)$ & 79.44 to $385\left(175^{\circ} \mathrm{F}\right.$ to $\left.725^{\circ} \mathrm{F}\right)$ \\
\hline
\end{tabular}

The TES system is designed to allow the reactor to run continuously at $\sim 100 \%$ power over a wide range of operating conditions. During periods of excess capacity, bypass steam is directed to the TES unit through the auxiliary bypass valves where it condenses on the shell side of the IHX. TES fluid is pumped from the Cold Tank to the Hot Tank through the tube side of the IHX at a rate sufficient to raise the temperature of the TES fluid to some set point. The TES fluid is then stored in the Hot Tank at constant temperature. Condensate is collected in a hot well below the IHX and drains back to the main condenser, or can be used for some other low pressure application such as chilled water production, desalination, or feed heating [20]. Pressure relief lines connect the shell side of the IHX with the condenser to prevent over pressurization of the heat exchanger during periods of low condensation rate. A nitrogen cover gas dictates tank pressure using the ideal gas law. In previous work, details of the equation sets and solution strategy used for solving the charging system equations have been provided [21]. Tank sizes are a direct function of the designed $\Delta \mathrm{T}$ between the Hot Tank and Cold Tank. Smaller tank sizes can be achieved by increasing the $\Delta \mathrm{T}$ between the tanks. 


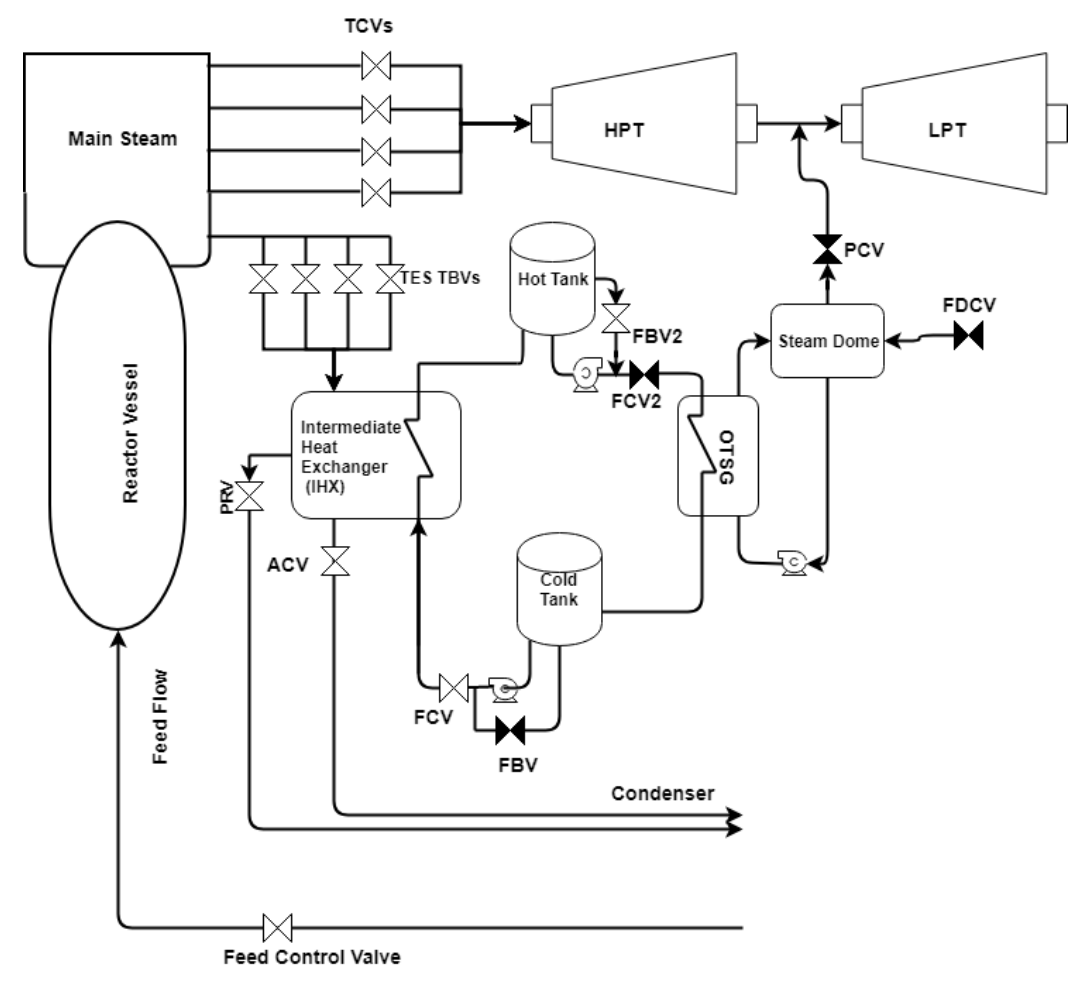

Figure 5: Schematic of an IPWR connected to a two-tank sensible heat thermal energy storage system, charging mode

\section{II.B.3. Charging System Control}

The TES charging system has five sets of valves used to control system parameters: auxiliary bypass valves, the TES flow control valve, the auxiliary control valve, pressure relief valves, and a stop valve.

The goal of the bypass flow controller is to provide bypass steam to the TES system at a rate sufficient to maintain the reactor at or near its nominal steady state value. The bypass valve controller generates an error signal based on the difference between measured bypass flow and a bypass flow demand signal. The bypass demand signal assumes the required bypass flow is proportional to the relative difference between the nominal full power turbine output and the instantaneous electric load plus a correction term (shim). The shim term modifies the demand signal such that reactor power is kept approximately constant. 
Flow from the cold tank to the hot tank is via a TES flow control valve. The TES flow control valve operates using a three-element controller where the first error signal is designed to maintain the TES fluid temperature leaving the Intermediate Heat Exchanger at some reference value. The second error signal is designed to roughly match the heat input into the TES fluid with the heat bypassed to the IHX.

The auxiliary control valve (ACV) maintains IHX hot well level. This valve operates on a threeelement controller based on the level of the IHX and the difference in mass flows into and out of the IHX. Pressure relief valves (PRVs) have been installed in the IHX to mitigate pressure increases. Should pressure reach an upper set point the valves will open and will not close until the pressure falls below a lower set point. The only parameters directly controlled during charging mode operation of the TES system are the IHX exit temperature on the inner loop and the level in the IHX. All other variables including IHX pressure, tank levels, inner loop mass flow rate, and heat transfer across the IHX are determined from the mass, energy, and momentum balances on the system. The momentum equations have a built-in time varying loss value that is dependent on valve position as well as a constant loss value that is associated with losses inherent in the line. All valves in the system are modeled as linear valves.

A stop valve (not shown) is placed in the flow line between the cold tank and hot tank to ensure tank pressure and level stay below designated set points. Should either the pressure or level set points be exceeded the stop valve will close and TES fluid flow between the tanks will cease. A redundant control on level is that the volume of Therminol-66 in the system is less than the total volume of either tank.

\section{II.B.4. Discharge System Design}

Converse to the charging mode, during periods of peak demand, or when process steam is desired, the system is discharged by pumping TES fluid from the Hot Tank to the Cold Tank through the tube side of a

Once Through Steam Generator (OTSG) producing a saturated liquid-vapor mixture. This two-phase mixture flows into a steam dome where it is separated into the gas and liquid phases. As illustrated in Figure 6 , this saturated steam can then be reintroduced into the power conversion cycle for electricity production 
or directed to some other application through the Pressure Control Valve (PCV) at the exit of the steam dome. For operation as an electrical peaking unit, steam is assumed to be reintroduced prior to the moisture separator/reheaters before entering the low pressure turbine. This allows the flow streams from the steam dome and high pressure turbine exhaust to combine and eliminates any moisture that may be present prior to entering the low pressure turbine. As in the charging mode a nitrogen cover gas dictates the Hot and Cold Tank pressures. Governing equations for the steam dome/steam generator model are discussed below.

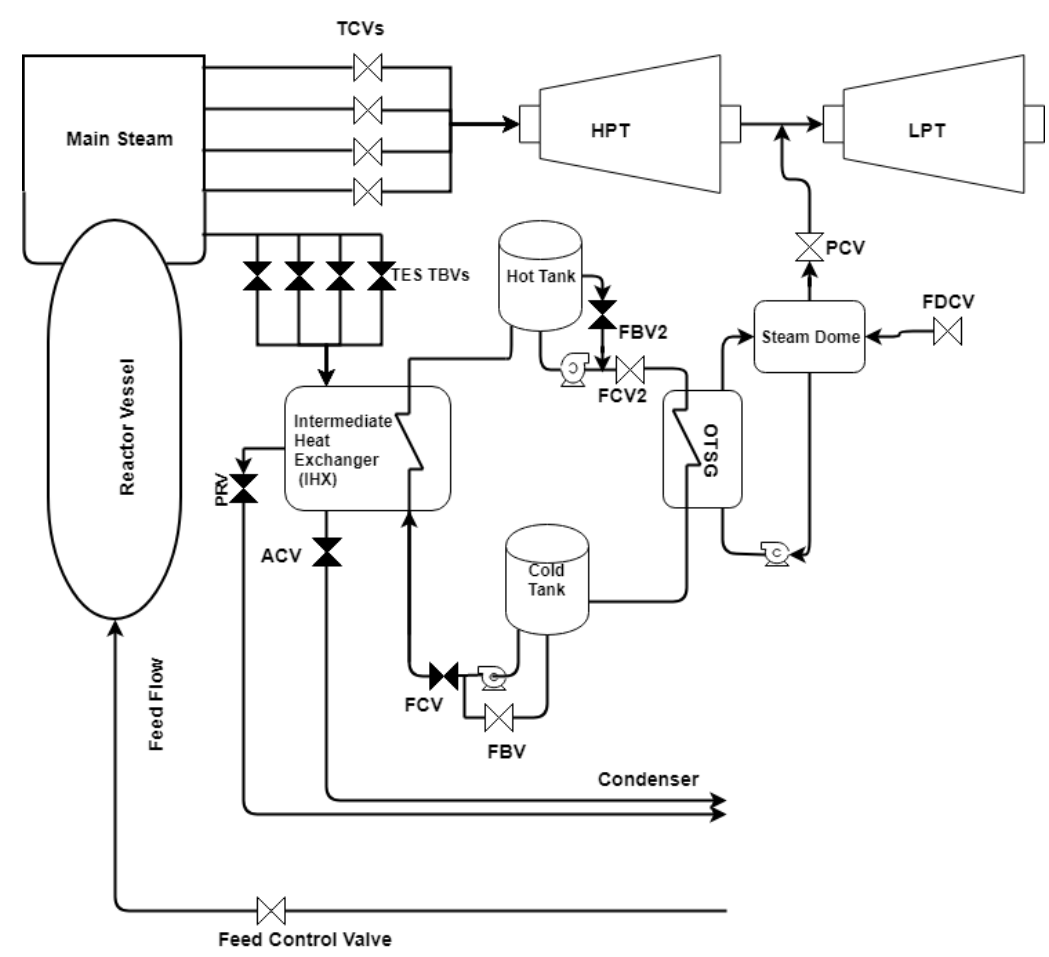

Figure 6: Schematic of an IPWR connected to a two-tank sensible heat thermal energy storage system, discharge mode.

\section{II.B.5. Steam Generator/Steam Dome Model Development}


A three equation Global Compressibility Model is assumed for the shell side of the steam generator, where thermodynamic equilibrium is assumed between the phases. The steam dome model assumes the vapor region is saturated and the liquid region is subcooled. It is currently assumed a pump will be used to provide a constant flow rate between the liquid region of the steam dome and the steam generator inlet. This can be changed later to eliminate the pump and allow for natural circulation to drive the steam generator flow if desired.

\section{OTSG (Shell Side) Equation Set}

Mass

$$
V_{j}\left\{\frac{\rho_{j}^{t+\Delta t}-\rho_{j}^{t}}{\Delta t}\right\}+\rho_{j+1 / 2}^{t} \mathrm{v}_{j+1 / 2}^{t+\Delta t} A_{j+1 / 2}-\rho_{j-1 / 2}^{t} \mathrm{v}_{j-1 / 2}^{t+\Delta t} A_{j-1 / 2}=0
$$

$j=1, n$ where $n$ is the number of computational nodes to represent the steam generator

Energy

$$
\begin{aligned}
& V_{j}\left\{\frac{\rho u_{j}^{t+\Delta t}-\rho u_{j}^{t}}{\Delta t}\right\}+\rho u_{j+1 / 2}^{t} \mathrm{v}_{j+1 / 2}^{t+\Delta t} A_{j+1 / 2}-\rho u_{j-1 / 2}^{t} \mathrm{v}_{j-1 / 2}^{t+\Delta t} A_{j-1 / 2} \\
& =-P^{t}\left\{\mathrm{v}_{j+1 / 2}^{t+\Delta t} A_{j+1 / 2}-\mathrm{v}_{j-1 / 2}^{t+\Delta t} A_{j-1 / 2}\right\}+\dot{q}_{j}^{t} \\
& -\left\{\frac{\alpha_{l} \alpha_{g} \rho_{f} \rho_{g}}{\rho}\left(u_{f g}+P_{S G} v_{f g}\right) \mathrm{v}_{r} A_{x S G}\right\}_{j-1 / 2}^{j+1 / 2, t}
\end{aligned}
$$

State Equations

$$
\begin{gathered}
\rho=\rho_{l}\left(u_{l}, P\right) \text { or } \rho=\alpha_{l} \rho_{l}+\alpha_{g} \rho_{g} \\
\rho u=\rho\left(u_{l}, P\right) u_{l} \quad \text { or } \rho u=\alpha_{l} \rho_{l} u_{l}+\alpha_{g} \rho_{g} u_{g}
\end{gathered}
$$

\section{$\underline{\text { Steam Dome Equation Set }}$}

Liquid Mass 


$$
\begin{aligned}
& V_{S D}\left\{\frac{\alpha_{l} \rho_{l}^{t+\Delta t}-\alpha_{l} \rho_{l}^{t}}{\Delta t}\right\}=\rho_{F D}^{t} \mathrm{v}_{F D C V}^{t+\Delta t} A_{F D C V}+\alpha_{l, S G}^{t} \rho_{f}^{t} \mathrm{v}_{S G, \text { exit }}^{t+\Delta t} A_{S G, \text { exit }} \\
& -\rho_{l, S D}^{t} \mathrm{v}_{S G, \text { entrance }}^{t+\Delta t} A_{S G, \text { entrance }}-\left.\frac{\alpha_{l} \alpha_{g} \rho_{f} \rho_{g} \mathrm{v}_{r}}{\rho}\right|_{S G, \text { exit }} ^{t} A_{S G, \text { exit }}
\end{aligned}
$$

Total Mass

$$
\begin{aligned}
& V_{S D}\left\{\frac{\rho_{S D}^{t+\Delta t}-\rho_{S D}^{t}}{\Delta t}\right\}=\rho_{F D}^{t} \mathrm{v}_{F D C V}^{t+\Delta t} A_{F D C V}+\rho_{S G}^{t} \mathrm{v}_{S G}^{t+\Delta t} A_{x S G} \\
& -\rho_{l, S D}^{t} \mathrm{v}_{S G, \text { entrance }}^{t+\Delta t} A_{S G, \text { entrance }}-\rho_{g}^{t} \mathrm{v}_{g}^{t+\Delta t} A_{\text {Steamline }}
\end{aligned}
$$

Total Energy

$$
\begin{aligned}
& V_{S D}\left\{\frac{\rho u_{S D}^{t+\Delta t}-\rho u_{S D}^{t}}{\Delta t}\right\}=\left(\rho_{F D} u_{F D}+P_{S D}\right)^{t} \mathrm{v}_{F D C V}^{t+\Delta t} A_{F D C V}+\left(\rho u_{S G, \text { exit }}+P_{S D}\right)^{t} \mathrm{v}_{S G, \text { exit }}^{t+\Delta t} A_{S G, \text { exit }} \\
& -\left(\rho_{l} u_{l, S D}+P_{S D}\right)^{t} \mathrm{v}_{S G, \text { entrance }}^{t+\Delta t} A_{S G, \text { entrance }}-\left(\rho_{g} u_{g}+P_{S D}\right)^{t} \mathrm{v}_{g}^{t+\Delta t} A_{S t \text { teamline }} \\
& +\left\{\frac{\alpha_{l} \alpha_{g} \rho_{f} \rho_{g}}{\rho}\left(u_{f g}+P_{S D} v_{f g}\right)^{t} \mathrm{v}_{r} A_{S G}\right\}_{S G, \text { exit }}^{t}
\end{aligned}
$$

State Equations

$$
\begin{gathered}
\left(\alpha_{l} \rho_{l}\right)_{S D}=\alpha_{l} \rho_{l}\left(u_{l, S D}, P_{S D}\right) \\
\rho_{S D}=\alpha_{l} \rho_{l}\left(u_{l, S D}, P_{S D}\right)+\alpha_{g} \rho_{g}\left(P_{S D}\right) \\
\rho u_{S D}=\alpha_{l} \rho_{l}\left(u_{l, S D}, P_{S D}\right) u_{l, S D}+\alpha_{g} \rho_{g}\left(P_{S D}\right) u_{g}
\end{gathered}
$$

Momentum Equations

$$
P_{S D}^{t+\Delta t}+\Delta P_{p, F C V}^{t}=P_{S G}^{t+\Delta t}+\rho_{l, S D}^{t}\left(K_{F C V \text { Line }}\right) \frac{\left(\mathrm{v}_{F C V}^{t+\Delta t}\right)^{2}}{2}
$$




$$
\begin{gathered}
P_{S D}^{t+\Delta t}=P_{L P T}^{t+\Delta t}+\rho_{l, S D}^{t}\left(K_{P C V}^{t}+K_{P C V \text { Line }}\right) \frac{\left(\mathrm{v}_{g}^{t+\Delta t}\right)^{2}}{2} \\
P_{\text {cond }}+\Delta P_{p, F D}^{t}=P_{S D}^{t+\Delta t}+\rho_{l, \text { cond }}^{t}\left(K_{F D C V}^{t}+K_{F D C V \text { Line }}\right) \frac{\left(\mathrm{v}_{F D}^{t+\Delta t}\right)^{2}}{2} \\
P_{S G}^{t+\Delta t}=P_{S D}^{t+\Delta t}+\rho_{S G, \text { exit }}^{t}\left(K_{S G}\right) \frac{\left(\mathrm{v}_{S G, \text { exit }}^{t+\Delta t}\right)^{2}}{2}
\end{gathered}
$$

These equations are nonlinear in the new time values. Using a Newton-Iteration scheme, equations (1)-(14) can be reduced to a $(n+2) \times(n+2)$ matrix providing solutions for the new iterate $(k+1)$ values $\mathbf{v}_{F C V}^{k+1}, \mathbf{v}_{1+1 / 2 \ldots .}^{k+1} \mathbf{v}_{j+1 / 2}^{k+1}, \quad \mathbf{v}_{S G}^{k+1}, P_{S G}^{k+1}, P_{S D}^{k+1}$ where $\mathrm{n}$ is the number of steam generator nodes. The remaining new iterate values can be obtained directly by back substitution. The equations are iterated to convergence based on the maximum relative difference for any single variable between iterations. The converged values become the solution for the new time values.

\section{Equations for tube side (Inner Loop) discharge mode}

Tube Side Energy Equation

$$
\begin{gathered}
V_{j} \rho_{T E S} c_{p, T E S}\left\{\frac{T_{j}^{t+\Delta t}-T_{j}^{t}}{\Delta t}\right\}+\dot{m}_{T E S}^{t+\Delta t} c_{p, T E S}\left(T_{j}^{t+\Delta t}-T_{j-1}^{t+\Delta t}\right)=-\dot{q}_{j}^{t+\Delta t} \\
\dot{q}_{j}^{t+\Delta t}=(U A)_{j}^{t}\left(T_{j}^{t+\Delta t}-T_{S G, j}^{t}\right)
\end{gathered}
$$

Rearranging

$$
T_{j}^{t+\Delta t}=\frac{\frac{V_{j} \rho_{T E S} c_{p, T E S}}{\Delta t} T_{j}^{t}+(U A)_{j}^{t} T_{O T S G_{j}}^{t}+\dot{m}_{T E S}^{t+\Delta t} c_{p, T E S} T_{j-1}^{t+\Delta t}}{\frac{V_{j} \rho_{T E S} c_{p, T E S}}{\Delta t}+(U A)_{j}^{t}+\dot{m}_{T E S}^{t+\Delta t} c_{p, T E S}}
$$

For node $1, \mathrm{~T}_{\mathrm{j}-1}=\mathrm{T}_{\mathrm{HT}}$

Hot Tank Mass Balance 


$$
-\dot{m}_{T E S}^{t+\Delta t}=\rho_{T E S} A_{H T}\left\{\frac{H_{H T}^{t+\Delta t}-H_{H T}^{t}}{\Delta t}\right\}
$$

Cold Tank Mass Balance

$$
\dot{m}_{T E S}^{t+\Delta t}=\rho_{T E S} A_{C T}\left\{\frac{H_{C T}^{t+\Delta t}-H_{C T}^{t}}{\Delta t}\right\}
$$

Momentum Equation

$$
P_{H T}^{t+\Delta t}+\Delta P_{p u m p 2}^{t}=P_{C T}^{t+\Delta t}+\frac{K_{F C V 2}^{t}\left(\dot{m}_{T E S}^{t+\Delta t}\right)^{2}}{2 A_{F C V 2}^{2} \rho_{T E S}}
$$

Cold tank energy balance

$$
M_{C T}^{t} c_{p}\left\{\frac{T_{C T}^{t+\Delta t}-T_{C T}^{t}}{\Delta t}\right\}=\dot{m}_{T E S}^{t+\Delta t} c_{p_{T E S}}\left(T_{S G_{E x i t}}^{t+\Delta t}-T_{C T}^{t+\Delta t}\right)-(U A)_{C T}^{t}\left(T_{C T}^{t+\Delta t}-T_{A m b}\right)
$$

Hot Tank Cover Gas

$$
\rho_{H T}^{t+\Delta t}=\frac{M_{\text {Fillgas }_{\mathrm{HT}}}}{A_{H T}\left(\text { Tank }_{\text {Height }}-\mathrm{H}_{\mathrm{HT}}^{\mathrm{t}+\Delta \mathrm{t}}\right)}
$$

\section{Cold Tank Cover Gas}

$$
\rho_{C T}^{t+\Delta t}=\frac{M_{\text {Fillgas }_{\mathrm{CT}}}}{A_{C T}\left(\text { Tank }_{\text {Height }}-\mathrm{H}_{\mathrm{CT}}^{\mathrm{t}+\Delta \mathrm{t}}\right)}
$$

Hot Tank Pressure (State Equation)

$$
P_{H T}^{t+\Delta t}=\rho_{H T}^{t+\Delta t} R T_{H T}^{t+\Delta t}
$$

Cold Tank Pressure (State Equation)

$$
P_{C T}^{t+\Delta t}=\rho_{C T}^{t+\Delta t} R T_{C T}^{t}
$$

The tube side equations also form a non-linear system that must be solved iteratively. A general Newton-Raphson iteration for this system had poor convergence characteristics due to the stiffness of the 
system. As an alternate approach, the equations were cast as a single non-linear equation in the TES flow rate that could be solved iteratively by Brent's algorithm [22]. This provides for a much more robust search.

\section{II.B.6. Discharge System Control}

The TES system can be operated in two different discharge modes. It can operate either as an electrical peaking unit to supplement electric production during times of high demand, or it can be used as a source of industrial steam production. Both modes are considered, each with its' own set of control algorithms.

\section{II.B.6.i. $\quad$ Electrical Peaking Unit}

Operation as a peaking unit assumes three control valves. A Pressure Control Valve (PCV) on the steam dome to ensure constant pressure steam conditions in the steam generator, an auxiliary Feed Control Valve between the condenser and the steam dome, and a Flow Control Valve on the tube side of the steam generator to regulate the amount of TES flow from the hot tank to the cold tank. Feed control to the steam dome is based on a standard three element controller where the error signals are steam dome level and steam flow/feed flow mismatch. The TES flow control assumes the TES flow demand is proportional to the maximum design TES flow plus a correction term (shim). The shim term modifies the demand signal such that the instantaneous electric load is met.

$$
\begin{gathered}
\text { Signal }_{F C V 2}=\frac{\dot{m}_{T E S 2 \text { demand }}-\dot{m}_{T E S}}{\dot{m}_{T E S 2 \text { ref }}} \\
\dot{m}_{\text {TES } 2 \text { demand }}=\dot{m}_{T E S 2 \text { ref }}\left(\frac{\dot{W}_{\text {target }}}{\dot{W}_{\text {Peaking }_{\text {Max }}}}\right)+\dot{m}_{T E S_{\text {shim }}} \\
\dot{m}_{T E S_{\text {shim }}}^{t+\Delta t}=\dot{m}_{T E S_{\text {shim }}}^{t}+\frac{K_{T E S_{\text {Shim }}} \dot{m}_{T E S_{\text {ref }}}\left(\dot{W}_{\text {target }}-\dot{W}_{\text {discharge }}\right) \Delta t}{\dot{W}_{\text {Peaking }_{\text {Max }}}}
\end{gathered}
$$


During times of discharge the reactor power is held constant by changing the feed demand on the main system Feed Control Valve that modulates flow through the main steam generator.

$$
\begin{gathered}
\text { Feed }_{\text {demand }}=\text { Flow }_{S G_{\text {Nominal }}}+\text { Feed }_{\text {Shim }} \\
\text { Feed }_{\text {Shim }}^{t+\Delta t}=\text { Feed }_{\text {Shim }}^{t}+\frac{K_{\text {Shim }} \text { Flow }_{S G_{\text {Nominal }}}\left(\dot{Q}_{\text {Ref }}-\dot{Q}_{t h}\right) \Delta t}{\dot{Q}_{\text {Ref }}}
\end{gathered}
$$

This modification allows the reactor to remain at approximately 100 percent power while the thermal energy storage system matches the increased turbine demand.

\section{II.B.6.ii. Industrial Steam Production}

As when configured as an electrical peaking unit, the control strategy for industrial steam production also assumes three control valves. A Pressure Control Valve (PCV) on the steam dome to ensure constant pressure steam conditions in the steam generator, a Feed Control Valve to allow for level control within the steam dome and a Flow Control Valve on the tube side of the steam generator to regulate the amount of TES flow from the hot tank to the cold tank. Feed control and pressure control strategies are the same as described for operation as an electrical peaking unit. The TES flow control assumes the required TES flow is proportional to the maximum design TES flow plus a correction term (shim). The shim term modifies the demand signal such that the instantaneous steam demand is met.

$$
\begin{aligned}
& \text { Signal }_{F C V 2}=\frac{\dot{m}_{T E S 2 \text { demand }}-\dot{m}_{T E S}}{\dot{m}_{T E S 2 \text { ref }}} \\
& \dot{m}_{T E S 2 \text { demand }}=\dot{m}_{T E S 2 r e f}\left(\frac{\dot{m}_{\text {Steamtarget }}}{\dot{m}_{\text {Steampeakref }}}\right)+\dot{m}_{T E S_{\text {shim }}} \\
& \dot{m}_{T E S_{\text {shim }}}^{t+\Delta t}=\dot{m}_{T E S_{\text {shim }}}^{t}+\frac{K_{T E S_{\text {Shim }}} \dot{m}_{T E S_{\text {ref }}}\left(\dot{m}_{\text {Steamtarget }}-\dot{m}_{\text {Steam }}\right) \Delta t}{\dot{m}_{\text {Steampeakref }}}
\end{aligned}
$$




\section{II.B.7. Charging/Discharge Cycle Realignment}

Variability in energy demand will dictate that over the course of time, whether it is days, weeks, or months, there will come a point where the discrepancy in time spent charging and discharging will result in one or the other tanks being full while leaving the other empty. When this occurs one of the two operating modes, charging or discharging, will need to be suspended until such a time that the tank levels can be brought back into their nominal operating range. Options to mitigate such scenarios are outlined below.

Scenario 1: Hot Tank is nearly full, and the system is charging

1. Decrease charging by decreasing the reactor power. This can be planned and does not require switching to full load follow operation.

2. Should the Hot Tank fill up the pressure relief valves in the IHX will open when the stopvalve between the Cold Tank and Hot Tank closes, shutting off TES fluid flow. Thus, all the bypass flow into IHX will pass through the pressure relief valves directly to the condenser, allowing the reactor to maintain operation at $100 \%$ power.

Scenario 2: Cold Tank is nearly full, and the system is discharging

1. Turn on additional peaking units. These can be smaller fossil fuel peaking units.

The mitigation of scenario 1 is easier in terms of infrastructure, especially if the system is deployed on a constrained grid. With this in mind most of the systems presented will be designed such that there is more charging than discharging when subjected to typical energy demands (electric or steam). 


\section{NHES Dynamic Simulations}

The goal of coupling a TES system to an IPWR is to operate the reactor at nominal full power, storing excess energy during periods of low demand and then recovering that energy during periods of high demand. To demonstrate such capabilities three sets of simulations were performed. The first set shows the system's ability to move thermal and mechanical stresses away from the primary and secondary sides of the reactor system over to the TES system. The second set demonstrates the ability of the TES system to operate as an electrical peaking unit. The last set of simulations shows the system's ability to provide process steam for ancillary applications. For these simulations an mPower style reactor with the geometry and design parameters specified in Table I was utilized. TES design parameters are given in Table III. For all simulations the term "electric demand" refers to the net demand required of the Reactor/TES system.

Components on the charging system were designed to accommodate $45 \%$ nominal steam flow from an mPower size IPWR while maintaining IHX pressure above 4.826MPa (700 psia). Discharge components were sized to accommodate approximately 45MWe of peaking capacity assuming a $33 \%$ balance of plant conversion rate.

Table III: TES Design Parameters for connection with an mPower size IPWR

\begin{tabular}{|l|l|}
\hline Parameter & Value \\
\hline TES Fluid & Therminol ${ }^{\circledR}-66$ \\
\hline Hot Tank Volume & $226,535 \mathrm{~m}^{3}$ \\
\hline Cold Tank Volume & $226,535 \mathrm{~m}^{3}$ \\
\hline IHX Reference Exit Temperature & $260{ }^{\circ} \mathrm{C}\left(500^{\circ} \mathrm{F}\right)$ \\
\hline Number of TBV's & 4 \\
\hline TES Maximum Steam Accommodation & $\sim 45 \%$ nominal steam flow \\
\hline Pressure Relief Valve Upper Setpoint & $5.377 \mathrm{MPa}(780 \mathrm{psia})$ \\
\hline Pressure Relief Valve Lower Setpoint & $5.240 \mathrm{MPa}(760 \mathrm{psia})$ \\
\hline Turbine Header Pressure & $\left.5.688 \mathrm{MPa}(825 \mathrm{psia})^{\mathrm{M}}\right)$ \\
\hline Shell Side (outer loop) IHX Volume & $101.94 \mathrm{~m}^{3}\left(3600 \mathrm{ft}^{3}\right)$ \\
\hline Number of Tubes & 19140 \\
\hline Length of Tubes & $11.25 \mathrm{~m}(36.9 \mathrm{ft})$ \\
\hline
\end{tabular}




\begin{tabular}{|l|l|}
\hline Tube Inner Diameter & $0.013 \mathrm{~m}(0.044 \mathrm{ft})$ \\
\hline Tube Outer Diameter & $0.018 \mathrm{~m}(0.058 \mathrm{ft})$ \\
\hline Steam Dome Reference Pressure & $1.379 \mathrm{MPa}\left(200 \mathrm{psia}^{3}\right)$ \\
\hline Steam Dome Volume & $509.7 \mathrm{~m}^{3}\left(18000 \mathrm{ft}^{3}\right)$ \\
\hline LPT reentrance point & $1.207 \mathrm{MPa}(175 \mathrm{psia})$ \\
\hline TES Steam Generator tube count & 32761 \\
\hline TES Steam Generator volume & $42.475 \mathrm{~m}^{3}\left(1500 \mathrm{ft}^{3}\right)$ \\
\hline TES Steam Generator Height & $9.144 \mathrm{~m}(30 \mathrm{ft})$ \\
\hline TES Steam Generator Thermal Conductivity & $10.3 \mathrm{Btu} / \mathrm{hr}^{-\mathrm{ft}-}{ }^{\circ} \mathrm{F}$ \\
\hline TES Steam Generator pitch to diameter ratio & 1.606 \\
\hline
\end{tabular}

\section{III.A. Charging System Capability}

This first set of simulations highlights the advantage of having a thermal storage system attached to the reactor as opposed to operating the reactor in load follow mode. These simulations focus only on the charging mode of the TES system. Operation as a peaking unit will be discussed later. A 24-hour simulation was run with an electric load profile representative of a typical summer day in an area with mixed commercial and residential characteristics [23]. The load profile was scaled such that the minimum load is approximately $60 \%$ of nominal full power. Time zero corresponds to midnight. Week or month long runs will show the same general trends as the daily cycle with the only distinction being in tank levels.

\section{III.A.1. Load Follow Operation}

As a basis for comparison, the SMR is operated in Load Follow mode, where the reactor power is modulated to match the electric demand. As shown in Figure 7 and Figure 8, the system is able to maneuver such that the turbine output is effectively identical to the electric demand, and the reactor power follows the load. Figure 9 illustrates that steam pressure is maintained throughout the run. For this simulation, a constant $\mathrm{T}_{\text {ave }}$ program was assumed with the corresponding control rod positions given in Figure 10. Four 
control banks are modeled. At the beginning of the maneuver, banks A-C are fully withdrawn, with D bank approximately $50 \%$ inserted. Over the course of the maneuver bank D moves to its full out position, and by the end of the transient has returned to its approximate starting point. The average primary coolant temperature varies by 4 degrees Celsius over the course of the run as illustrated in Figure 11 . The changes in core coolant temperatures, along with the changes in core power distribution and associated fuel temperatures result in additional thermal stresses to the system, especially if repeated for multiple cycles. Figure 12 and 14 show the variation in steam generator dryout location and feed temperature over the 24 hour run. The dryout location varies by $15 \%$ of the tube length, and represents a sharp temperature gradient. Repeated cycling of this location coupled with the significant variation in feed temperature can induce stresses that decrease the lifetime of the steam generator tubes. Of additional interest is the steam pressure downstream of the TCV (Turbine Impulse Pressure). As stated previously, steam conditions at this location are a strong function of the load profile and create additional challenges if connections to the TES system are made downstream of this point.

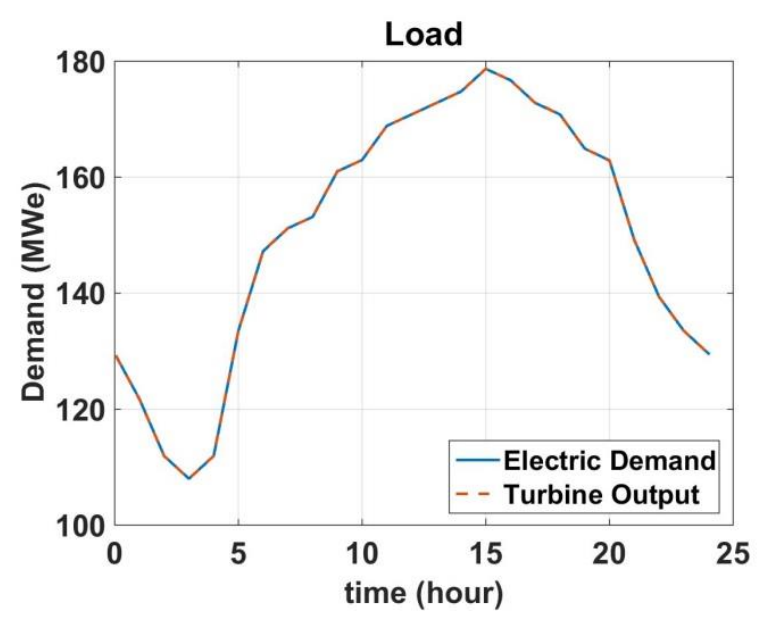

Figure 7: Turbine Output and Demand

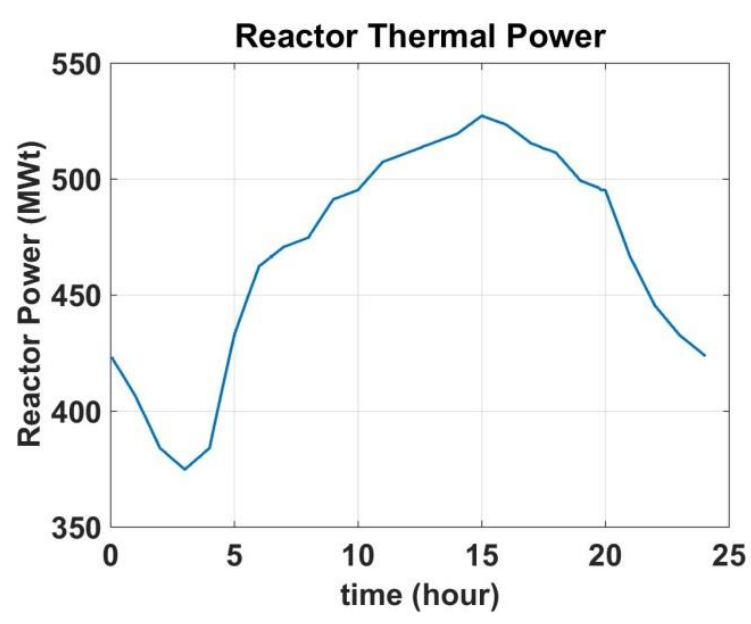

Figure 8: Reactor Power 


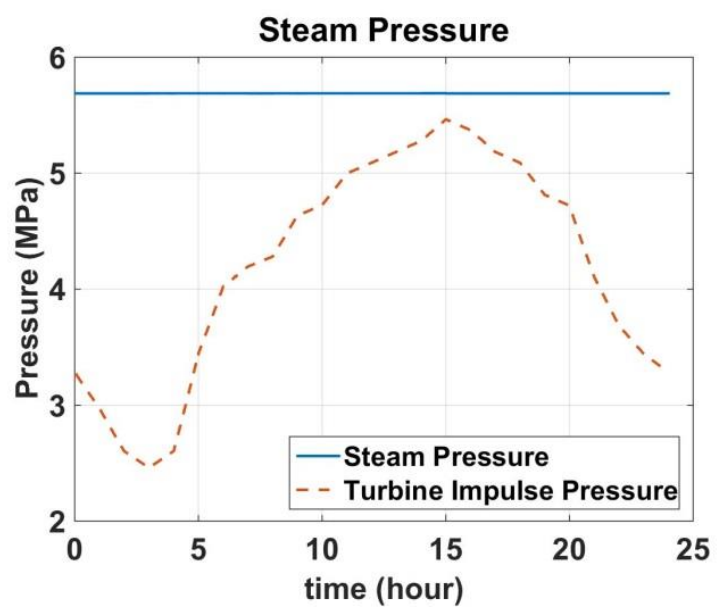

Figure 9: Steam Pressure

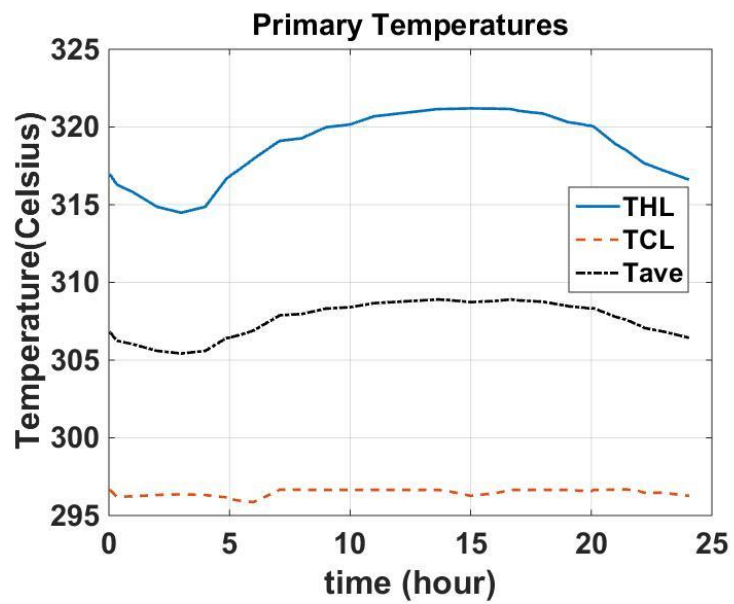

Figure 11: Primary Temperatures

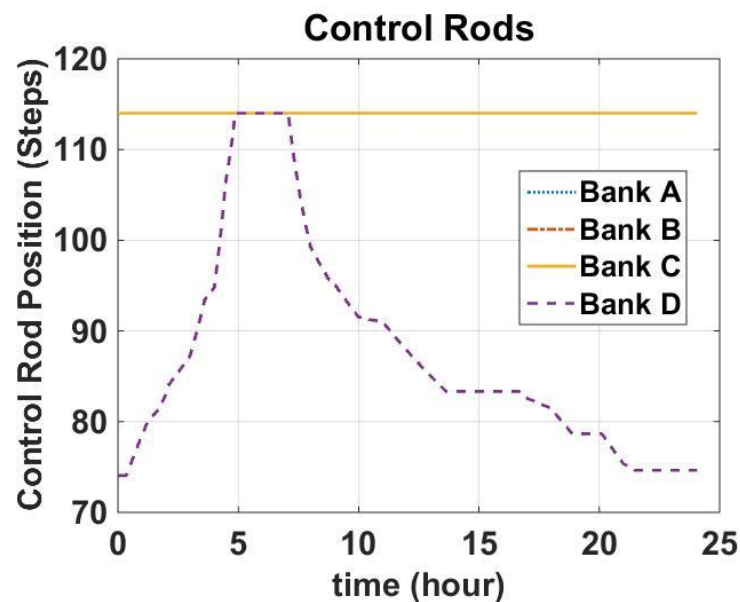

Figure 10: Control Rod Position

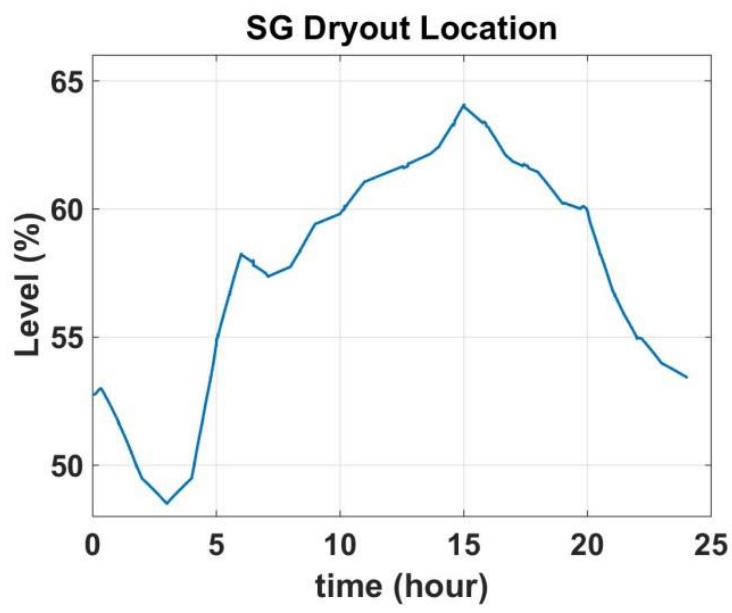

Figure 12: Steam Generator Dryout Location 


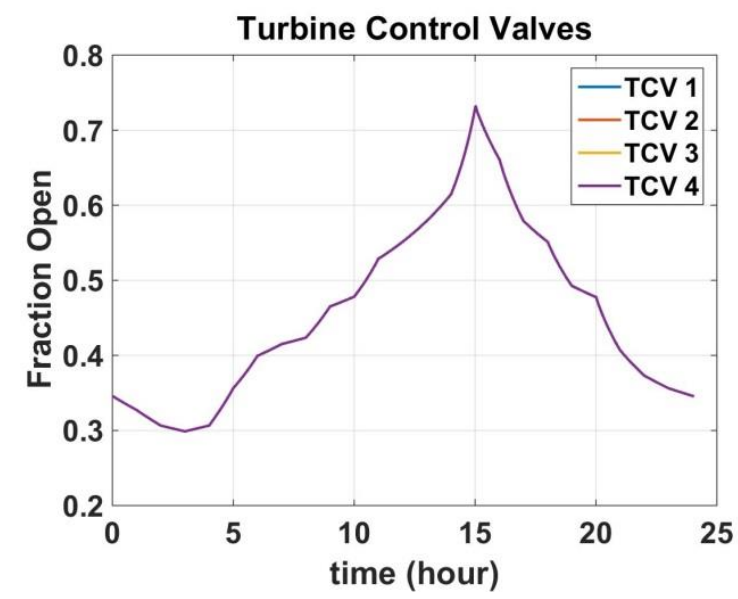

Figure 13: Turbine Control Valve Position (all TCVs move to same position)

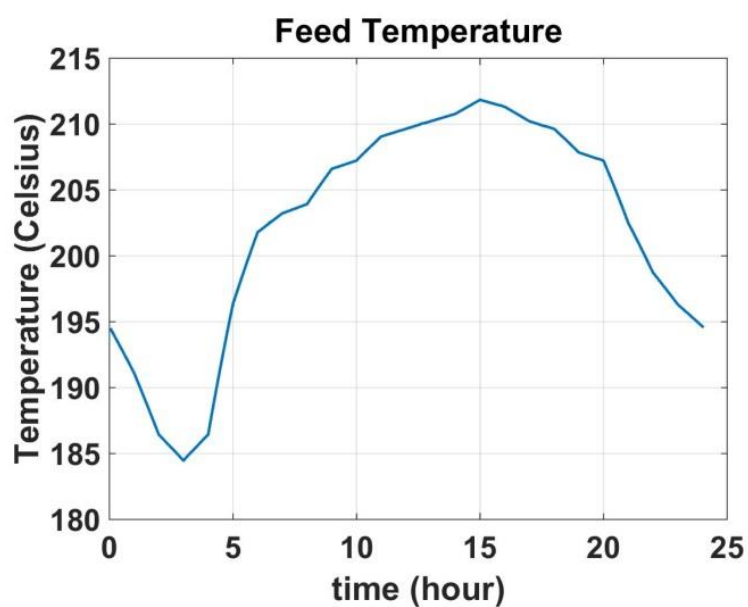

Figure 14: Temperature of feed water entering bottom of Steam Generator

\section{III.A.2. Reactor Coupled with TES Storage System (Charging only \\ Operation)}

The same 24 hour run was simulated with the TES system active. As illustrated in Figure 15 and Figure 16 the plant is able to maneuver such that the electric demand is satisfied while keeping reactor power effectively constant (oscillations are less than $2 \mathrm{MWt}$ as compared to hundreds of MW's in typical load follow maneuvers). Since reactor power, reactor coolant temperatures, and the steam generator dryout location were essentially constant, as shown in Figure 17 and Figure 18, this maneuver could be executed without control rod movement and the thermal/mechanical stresses associated with changes in temperatures and power distributions. The corresponding bypass flow to the TES system is shown in Figure 19. As would be expected, the bypass flow rate is essentially the inverse of the load profile. The steam generator dryout location varies by only $2 \%$ of the steam generator tube length for this simulation as compared with the $15 \%$ variation present during conventional load follow. Since feed temperature is a function of turbine impulse pressure, its behavior is unchanged from the load follow case. The TES fluid flow rate is shown in Figure 20 and closely follows the bypass flow rate. Steam generator and turbine impulse pressure are essentially unchanged from the Load Follow simulations. 


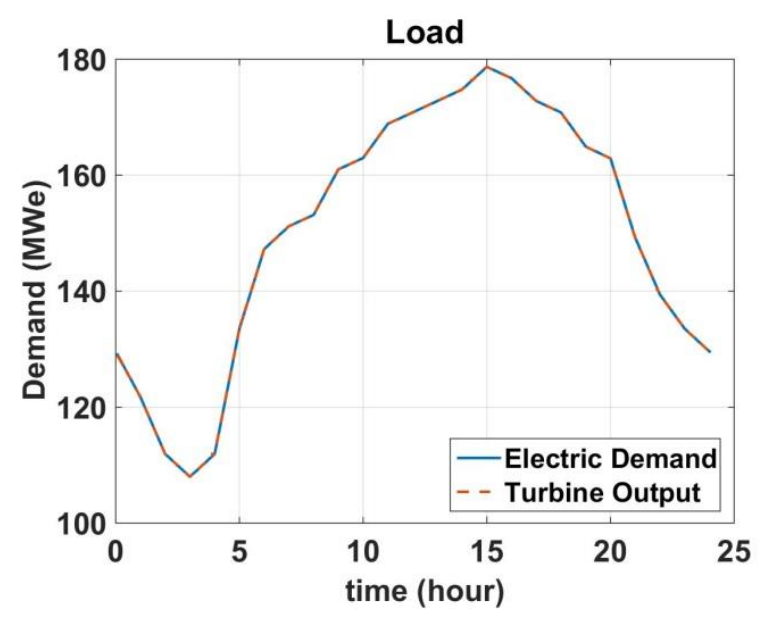

Figure 15: Turbine Output and Demand

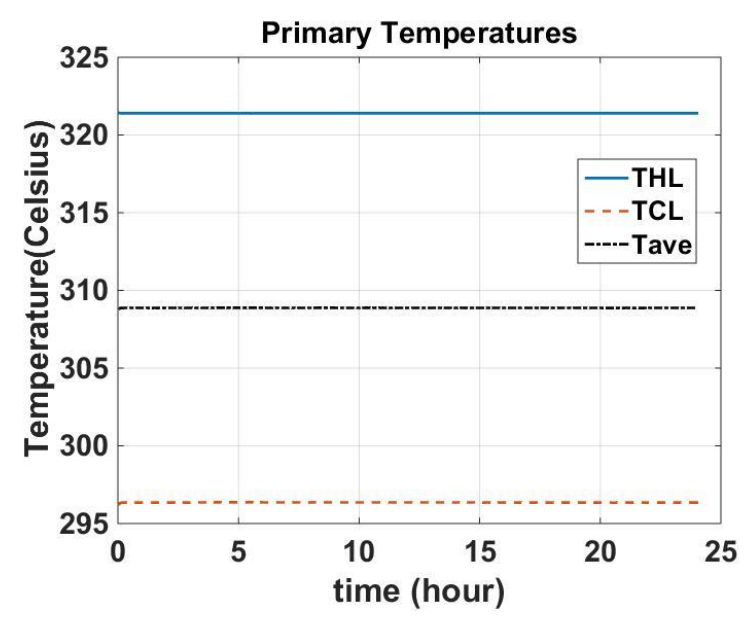

Figure 17: Primary Temperatures

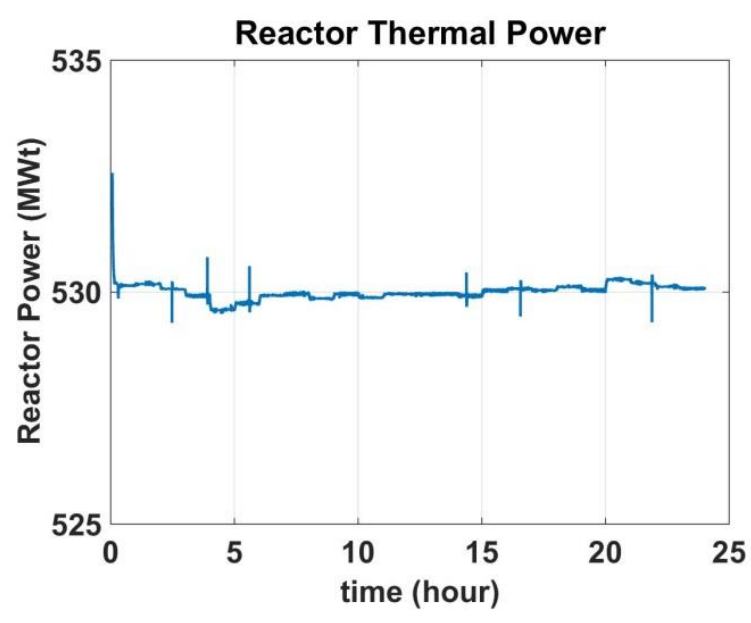

Figure 16: Reactor Power

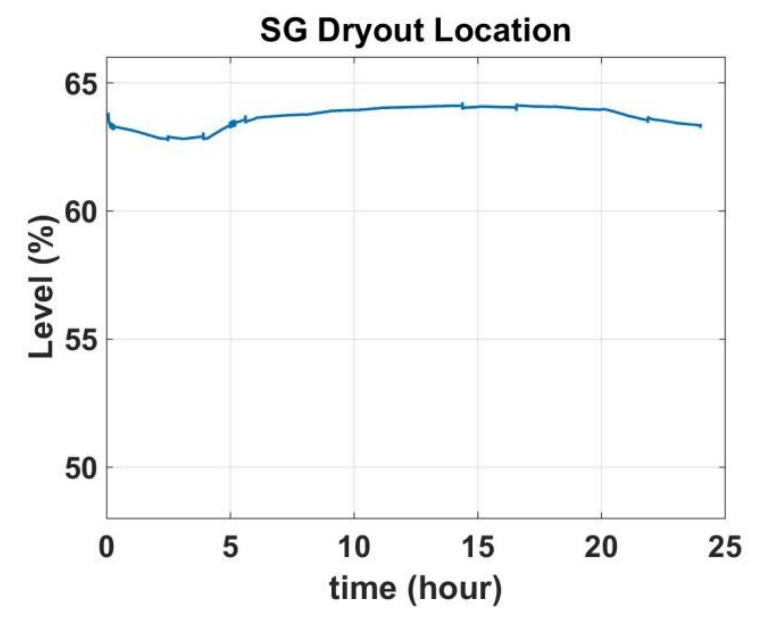

Figure 18: Steam Generator Dryout Location 


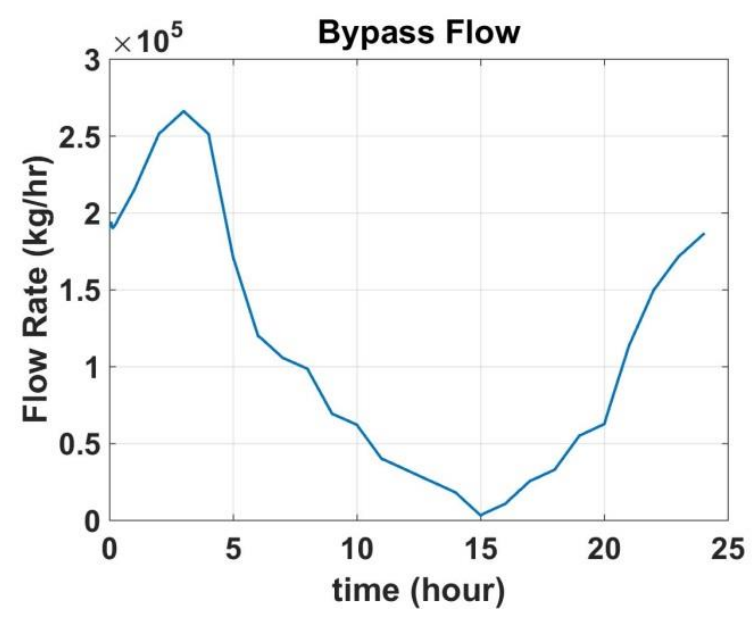

Figure 19: Bypass Flow into TES system

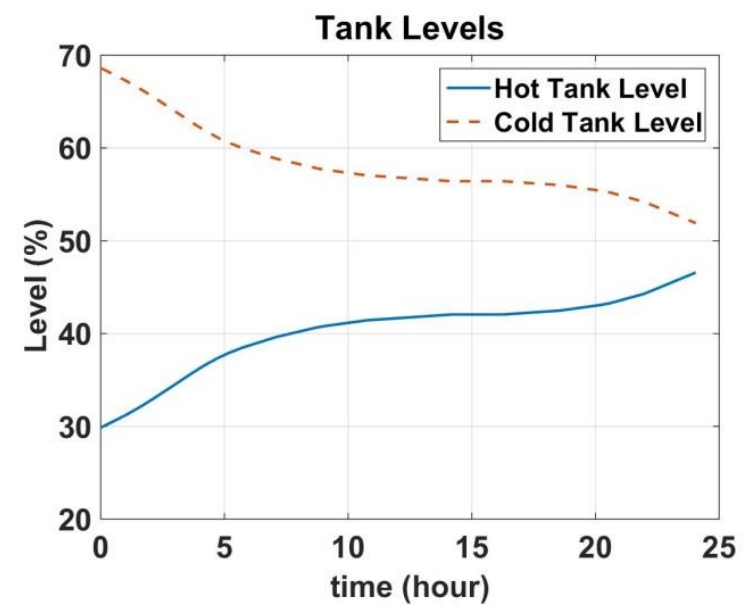

Figure 21: Hot and Cold Tank Levels

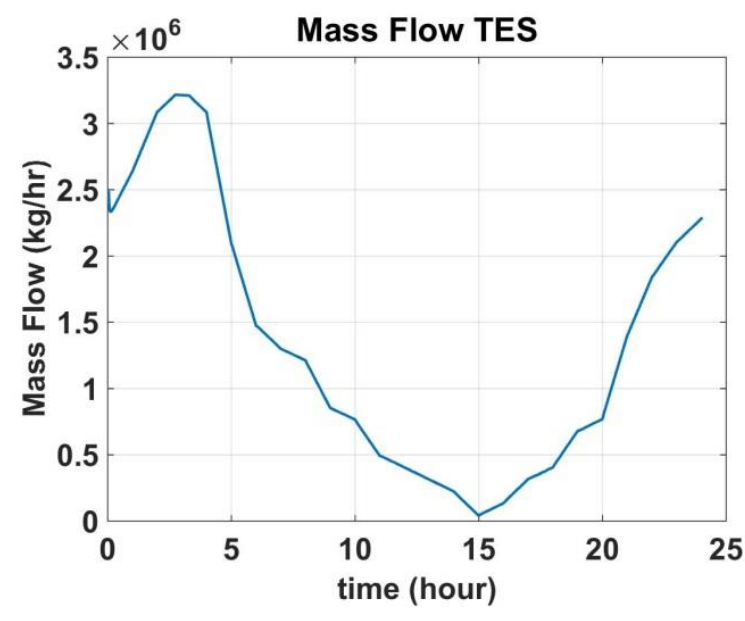

Figure 20: Flow of TES Fluid from Cold Tank to Hot Tank

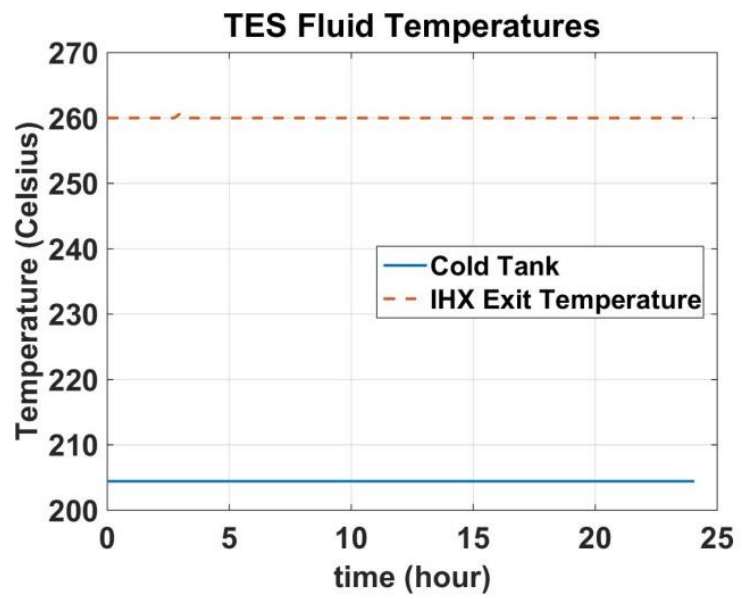

Figure 22: TES Temperatures

The hot and cold storage tank levels are given in Figure 21. For the load profile considered here, the tanks have more than enough capacity to accommodate the excess thermal energy in the system. Figure 22 demonstrates that the flow controller for the TES flow control valve (FCV) is effective in keeping the IHX exit fluid temperature at its target value. 


\section{III.A.3. Reactor Coupled with TES Storage System and intermittent}

\section{renewables}

An advantage of the TES system is the ability to accommodate the presence of intermittent energy sources on the grid, particularly solar energy generation that can vary depending on time of day or cloud cover. To illustrate these effects the load profile was modified to reflect upwards of 40MWe installed solar capacity as shown in Figure 23 and Figure 24. As indicated, turbine load is met while thermal power stays approximately constant as illustrated in Figure 25 and Figure 26. Figure 27 shows the bypass flow into the IHX is approximately an X-axis reflection of the net demand. The response of other system parameters is similar to that shown previously for the typical summer day. The TES system has the capacity to charge for the full 24 hour run as tank levels go from 30\% to 57\%, shown in Figure 28. Similar results have been obtained for a variety of load profiles with varying levels of renewable resources [21].

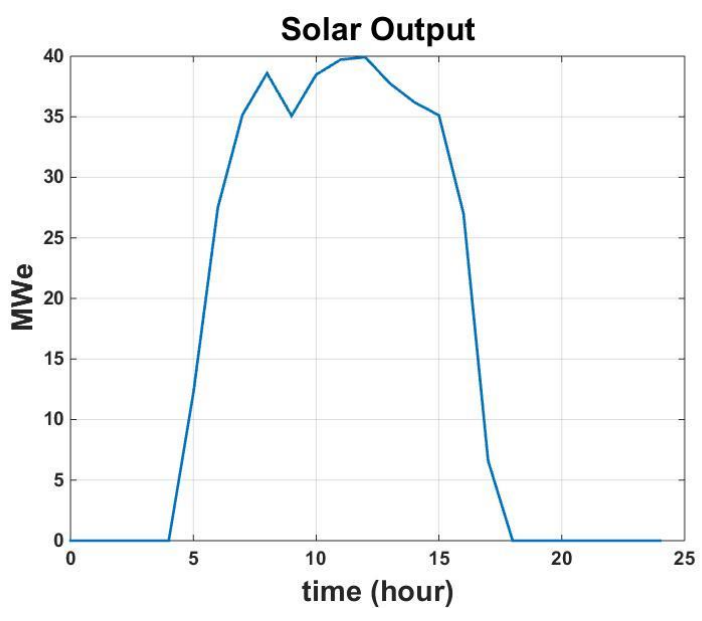

Figure 23: Typical Solar Output for a Summer Day

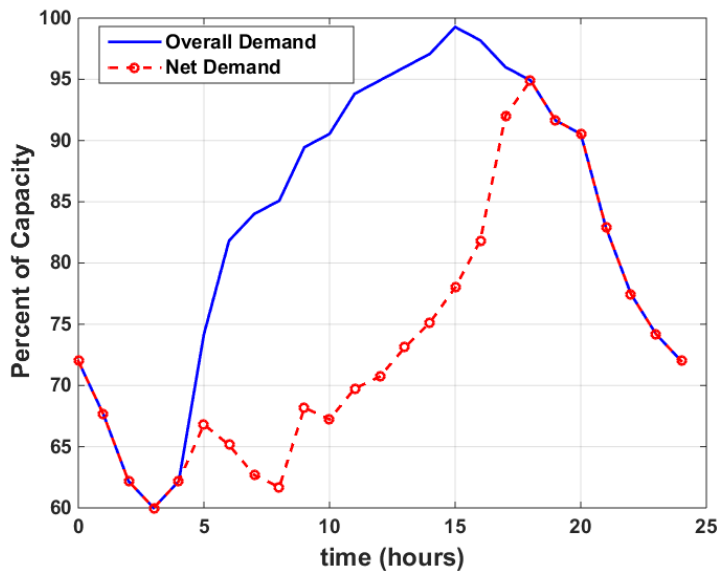

Figure 24: Demand profiles of a Typical Summer Day with and without Solar 


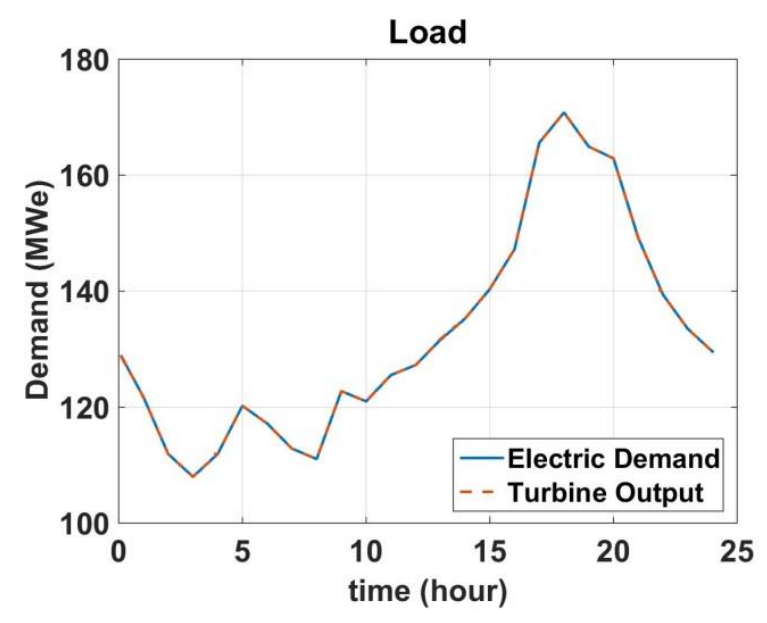

Figure 25: Turbine Load and Output

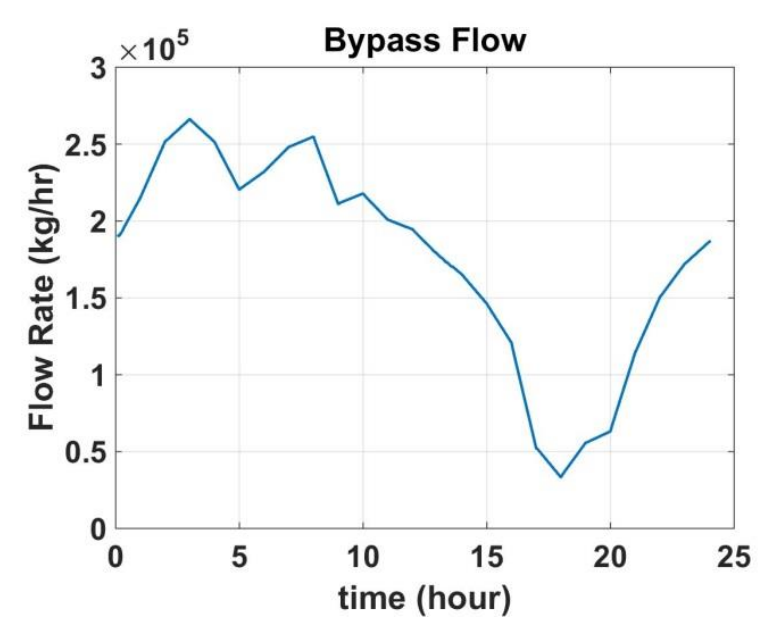

Figure 27: Auxiliary Bypass Flow

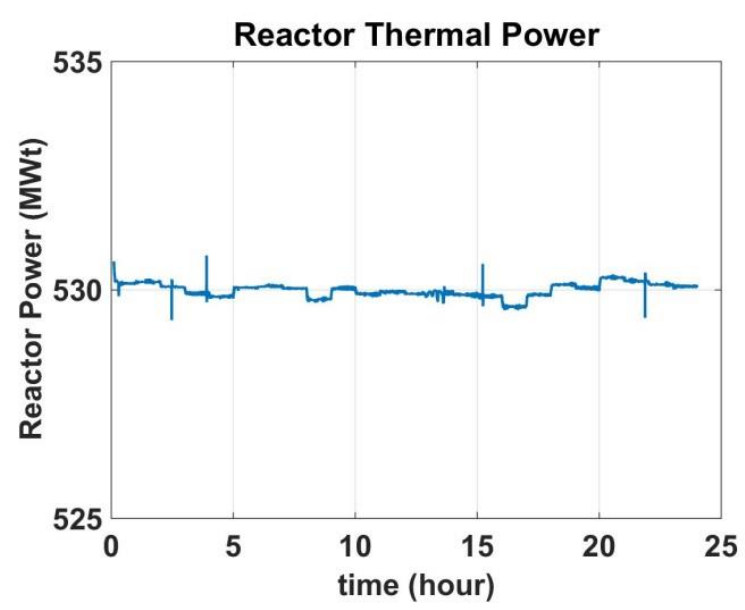

Figure 26: Reactor Power

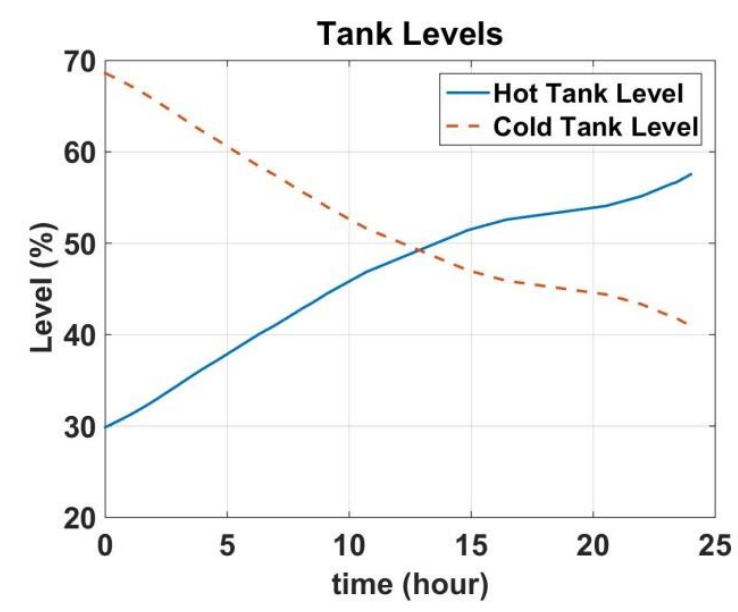

Figure 28: Hot and Cold Tank Levels

\section{III.B. Electrical Peaking Unit}

Previous results show the advantages of having a TES system as a means of heat storage and load management. This second set of simulations illustrates the TES system's ability to operate as an electrical peaking unit. The unit is designed to accommodate $\sim 35 \mathrm{MWe}$ peaking potential. It is assumed the low 
pressure turbine, generator and other Balance of Plant components have been sized to accept the additional thermal loads. The previous 24-hour electric load for a typical summer day was scaled so that for a typical summer day the integral amount of energy spent charging is $52.5 \%$ of the total energy spent charging and discharging as illustrated in Figure 29. The deployability of these systems requires that a single design be sized to accommodate a large range of load profiles. Three scenarios were considered: a typical summer day, a typical summer day with $15 \%$ (31.76MWe) maximum solar penetration to the grid, and a typical winter day. Since the cost of the TES fluid can be substantial [24], the amount of Therminol-66 in the tanks was drastically reduced from the $226,535 \mathrm{~m}^{3}\left(8,000,000 \mathrm{ft}^{3}\right)$ assumed in the previous charging-only simulations to $61,164 \mathrm{~m}^{3}\left(2,160,000 \mathrm{ft}^{3}\right)$. It should be noted that a load profile could be chosen purely for economic reasons. A system with this storage capability could be operated to store heat during times of low electric prices and then discharged during times of high electric prices. These simulations assume the system is the main source of power as opposed to a piece in a larger generation network where such a strategy is feasible.

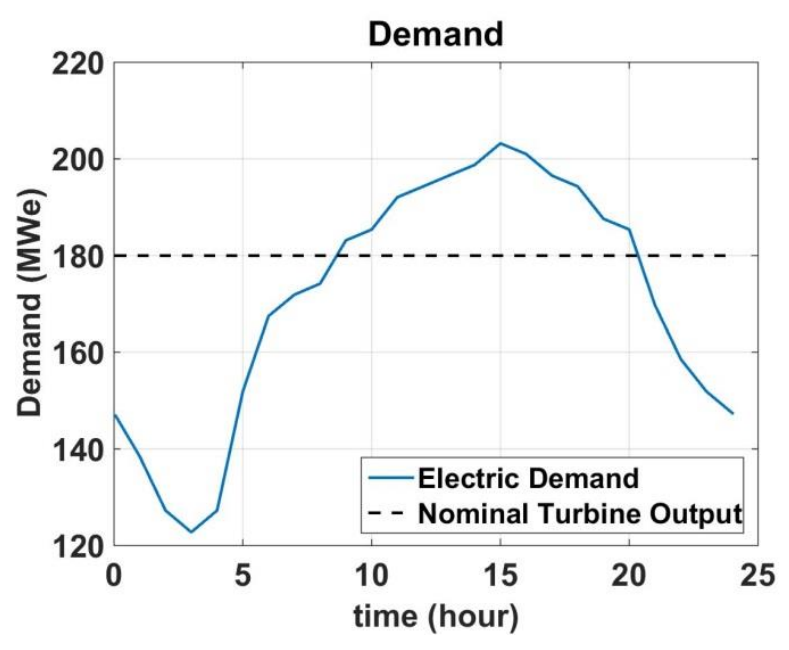

Figure 29: Electric Demand for a Typical Summer Day in a region scaled for charging/discharging operation with standard residential and commercial electrical needs. 


\section{III.B.1. Typical Summer Day}

As illustrated in Figure 30 and Figure 31, the TES system is able to maneuver such that the electric demand is satisfied while keeping reactor power effectively constant. Bypass flow, illustrated in Figure 32, is approximately an x-axis reflection of the load profile up until the load reaches the nominal turbine "rated" output of 180 MWe. The mass flow rate from the cold tank to the hot tank follows this same shape as seen in Figure 33. Over the 24 hour simulation period the tank levels oscillate about $25 \%$ of maximum as illustrated in Figure 34. During charging mode operation, the TES fluid temperature entering the hot tank is maintained at the reference set point as seen in Figure 35. When demand goes above the 180 MWe the charging mode shuts off and the discharge mode activates automatically. During this time the mass flow rate from the hot tank to the cold tank is modulated to ensure the electrical demand is being met as seen in Figure 36. From about $8 \mathrm{am}$ to $9 \mathrm{pm}$ the system is operating as an electrical peaking unit as illustrated in Figure 37. Once demand drops below $180 \mathrm{MWe}$, the discharge mode deactivates and charging mode operation is reinitiated.

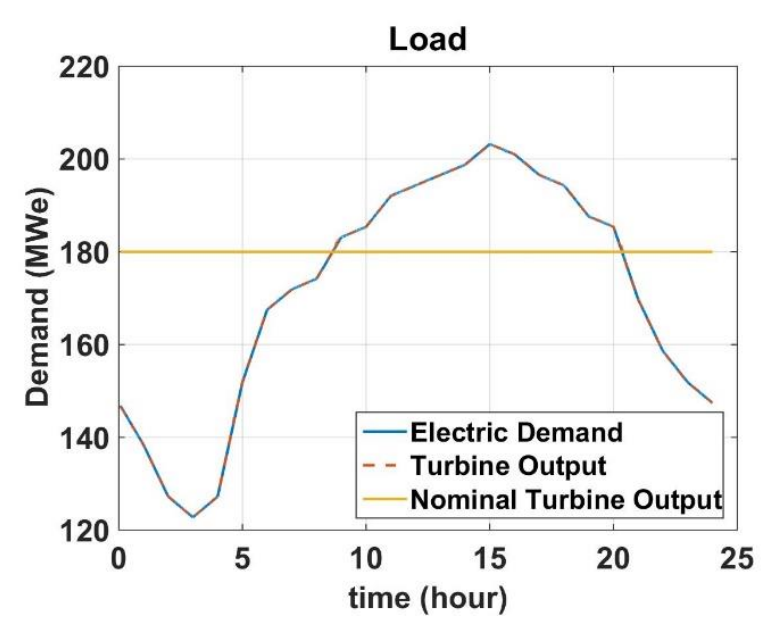

Figure 30: Turbine Load and Output

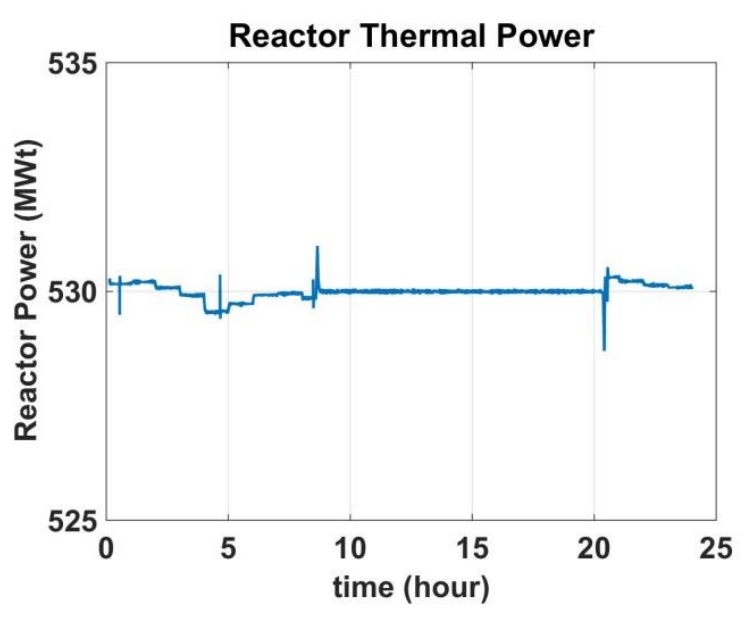

Figure 31: Reactor Power 


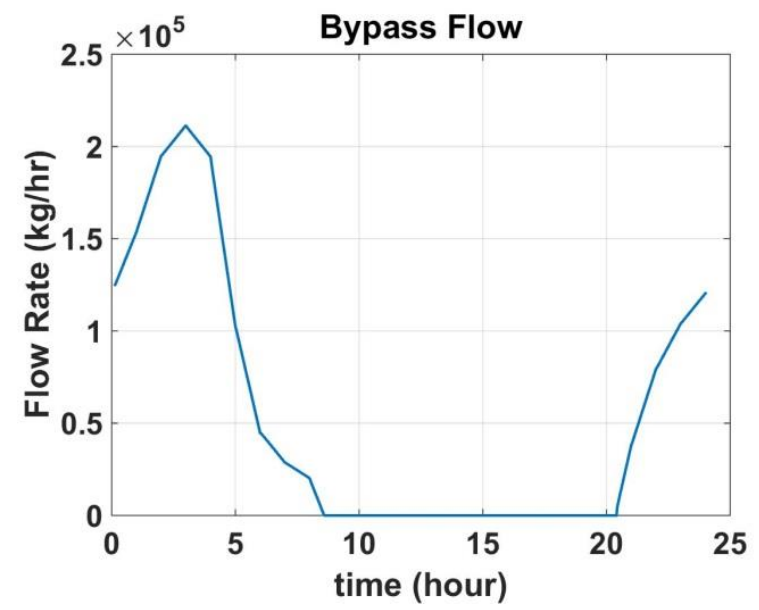

Figure 32: Auxiliary Bypass Flow

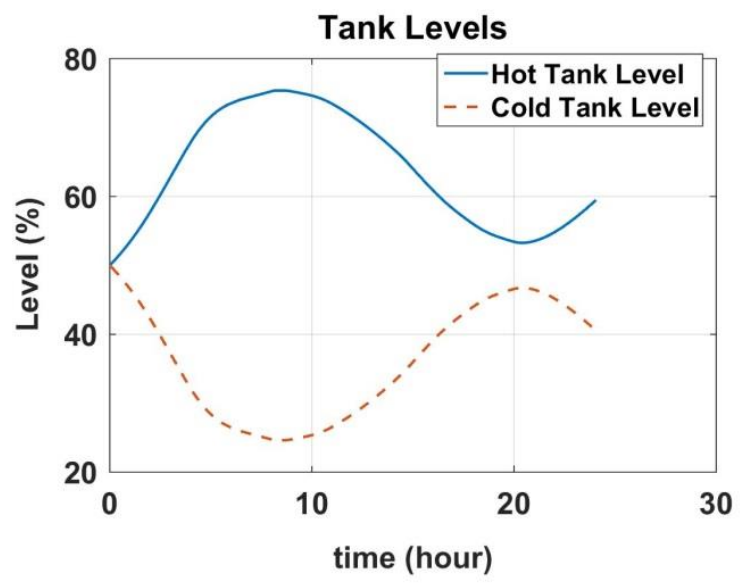

Figure 34: Hot Tank and Cold Tank Level

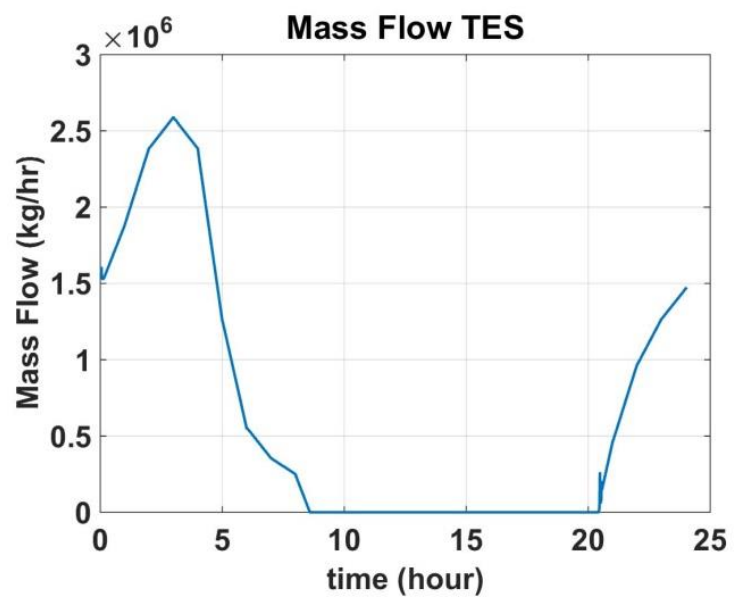

Figure 33: Flow of TES Fluid from Cold Tank to Hot Tank

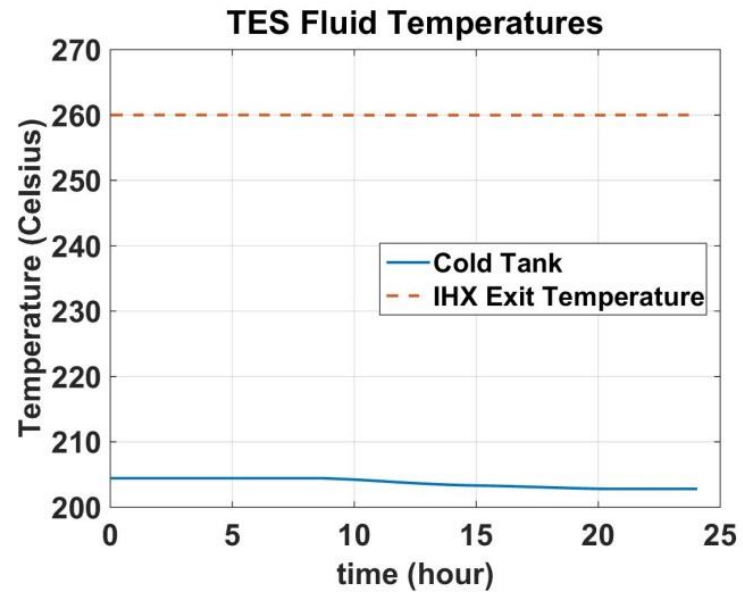

Figure 35: TES Fluid Temperature 


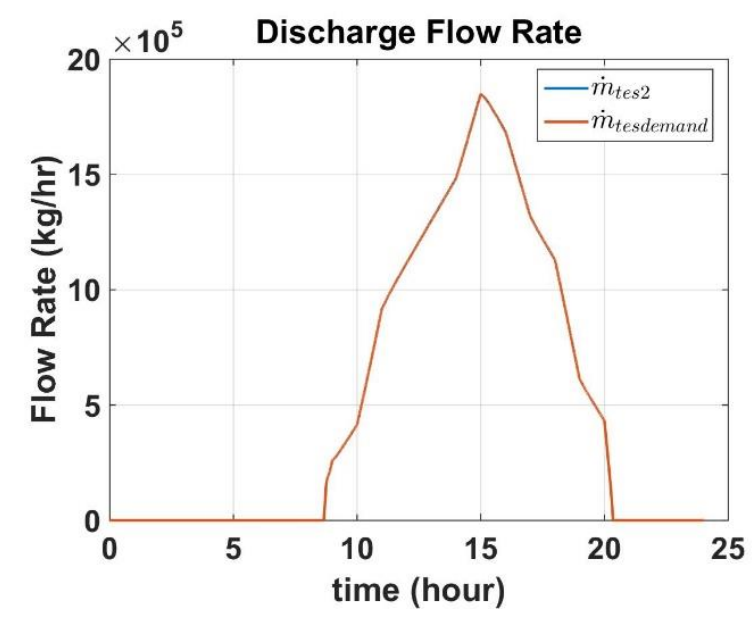

Figure 36: Flow of TES Fluid from Hot Tank to Cold Tank

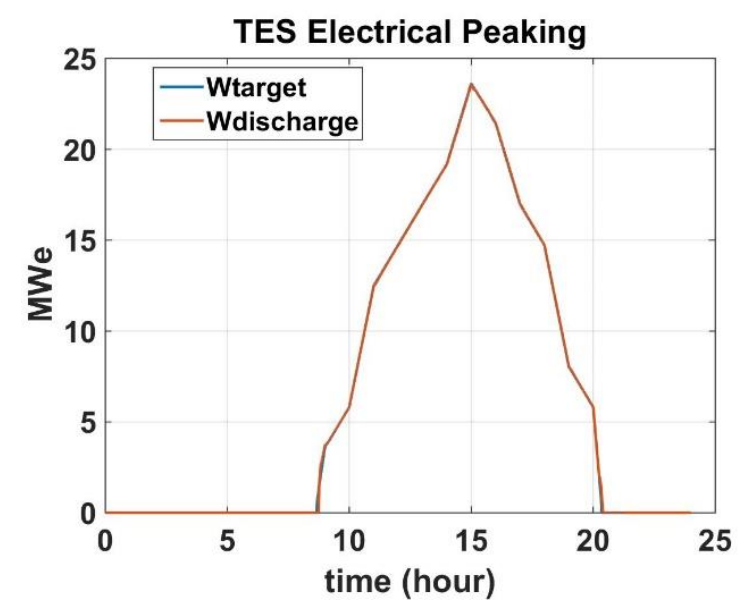

Figure 37: Electrical Peaking Output

\section{III.B.2. Typical Winter Day}

Along with typical diurnal electric demand there is also seasonal demand. The 24-hour simulation below is that of a typical winter day in the southeast United States [25]. System response is illustrated in Figures 38-45 and is similar to that for the typical summer day. The TES system is able to maneuver such that reactor power remains constant and turbine load is met over the 24 hour simulation period. For this simulation the tank levels oscillate about $25 \%$ with an increase in hot tank inventory of about $12-13 \%$. 


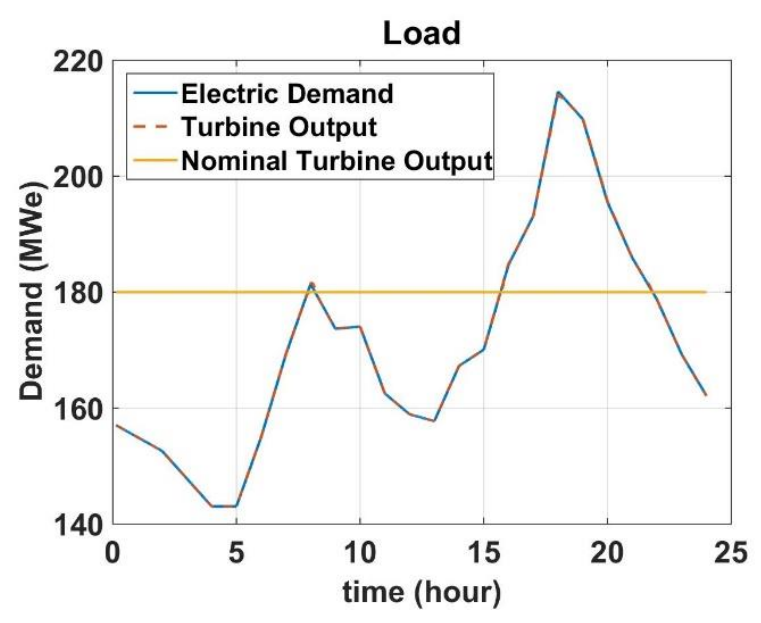

Figure 38: Turbine Output and Demand

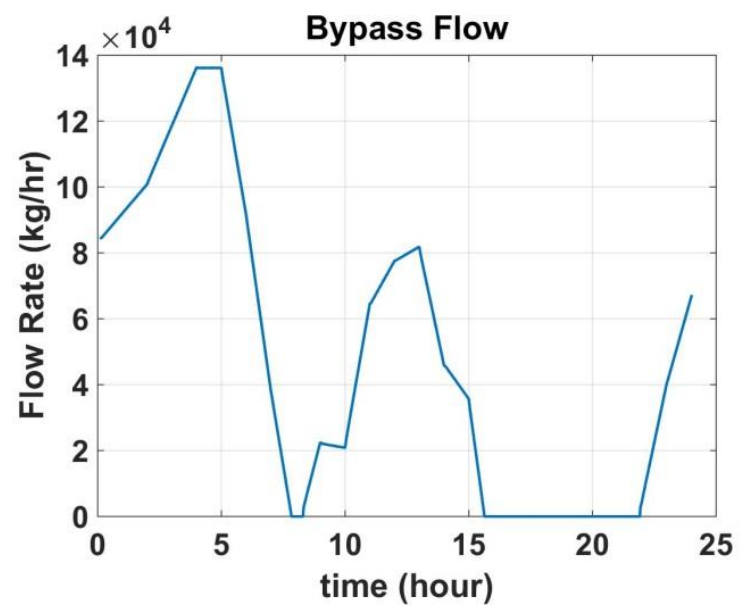

Figure 40: Auxiliary Bypass Flow

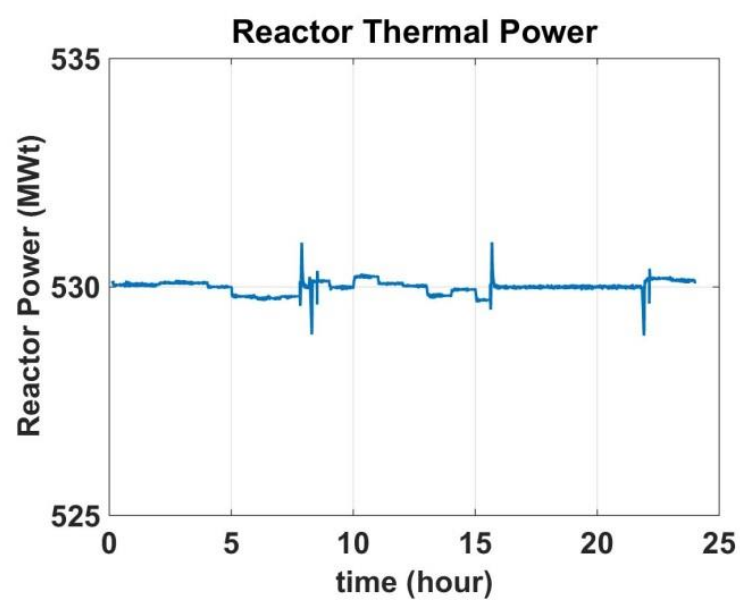

Figure 39: Reactor Power

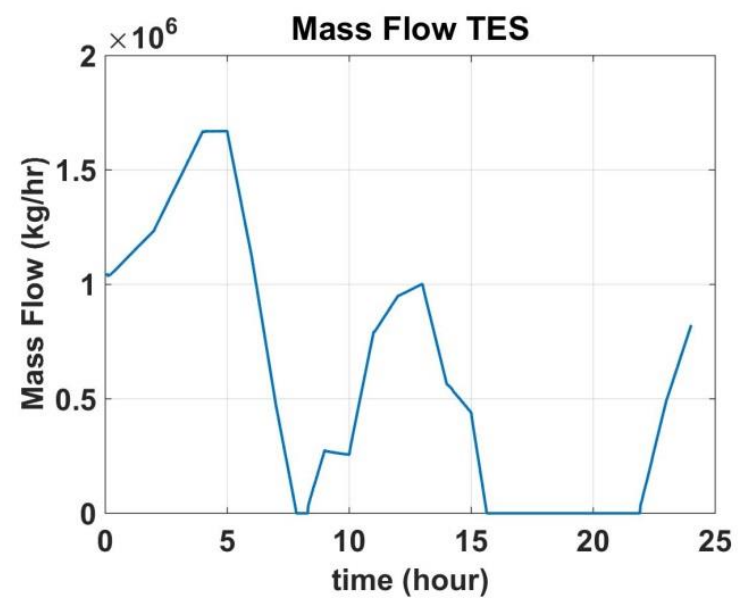

Figure 41: Flow of TES Fluid from Cold Tank to Hot Tank 


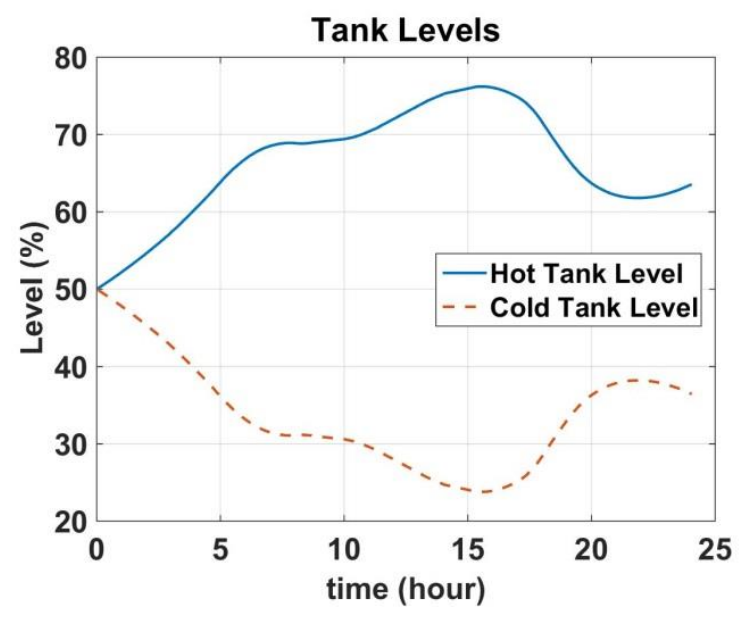

Figure 42: Hot Tank and Cold Tank Level

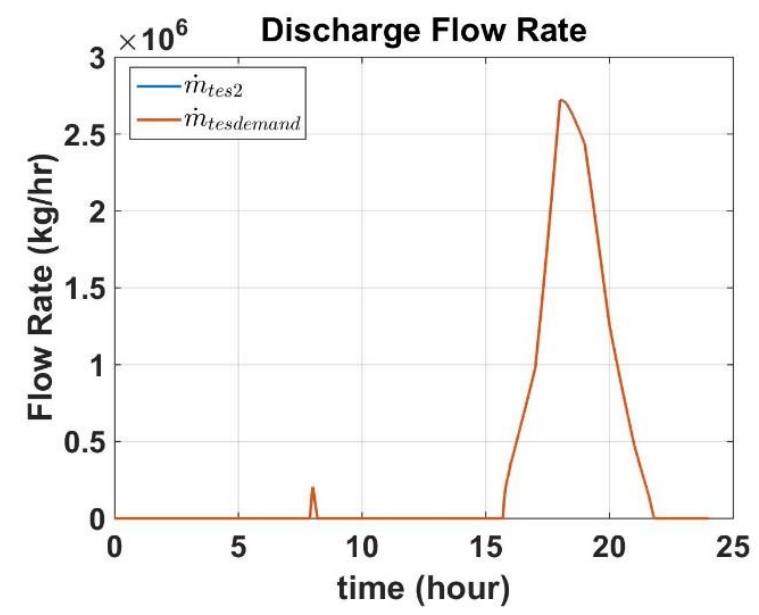

Figure 44: Flow of TES Fluid from Hot Tank to Cold Tank

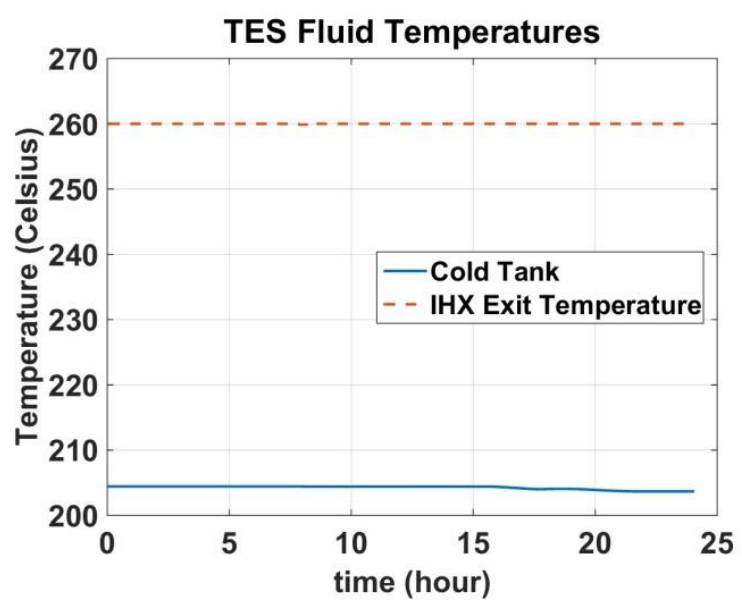

Figure 43: TES Fluid Temperature

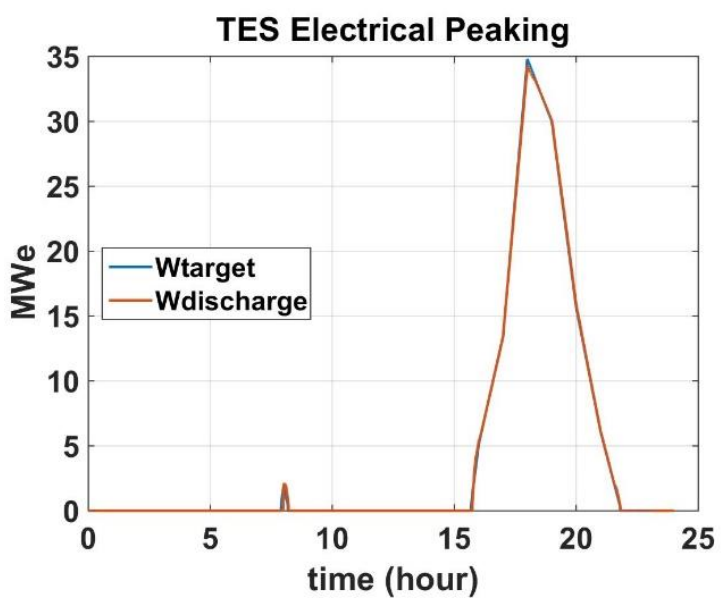

Figure 45: Electrical Peaking Output

\section{III.C. Extended Runs}

To illustrate system performance over extended operating times, the system was subjected to three different three-day simulations with $15 \%$ solar PV. The first simulation assumes three consecutive typical sunny summer days, the second assumes three typical summer days where the third day is cloudy, and the third assumes three winter days where day two is cloudy. On cloudy or rainy days solar panels are assumed 
to run at $10 \%$ capacity [26]. For these runs the electric demand was shifted upward so that on a typical summer day with $15 \%$ solar penetration the hot tank fills more than the cold tank. This allows the system to be more adaptable to times of low solar output (e.g. rain or cloud cover). Tank sizes were 61,164 $\mathrm{m}^{3}$ $\left(2,160,000 \mathrm{ft}^{3}\right)$ for all simulations, and were sufficient to accommodate all load profiles considered.

\section{III.C.1. Three Summer Days with 15\% Solar Penetration}

The first of the simulations is three consecutive sunny summer days with $15 \%$ solar penetration. Electric demand, turbine load and reactor thermal output are given in Figure 46 and Figure 47. Bypass flow into the TES system and TES fluid flow from the cold tank to the hot tank are shown in Figure 48 and Figure 49. Figure 50 illustrates the tank levels over the three-day run, with the hot tank ending up $30 \%$ fuller at the end of day three than at the start of day one. Cold tank temperature is not controlled, and fluctuates about five degrees Celsius over the three-day simulation. However, TES fluid temperature entering the hot tank is still maintained at the reference set point as seen in Figure 51.

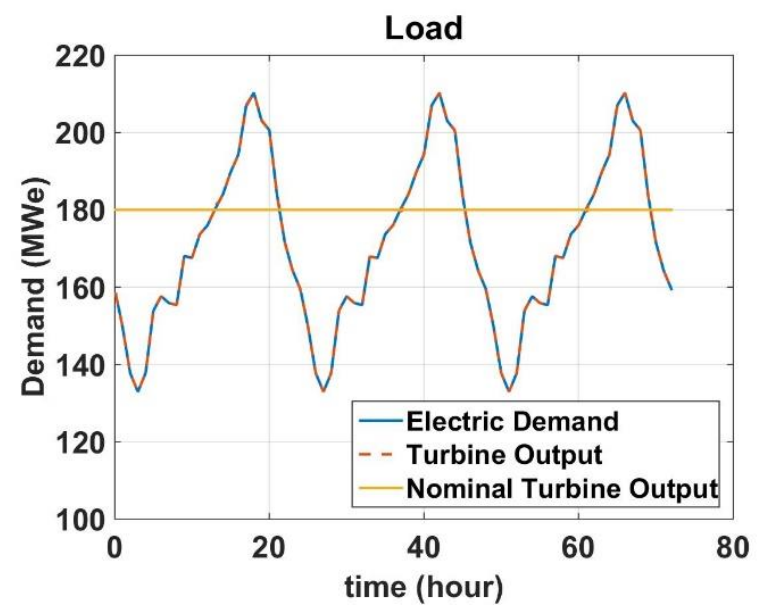

Figure 46: Turbine Output and Demand

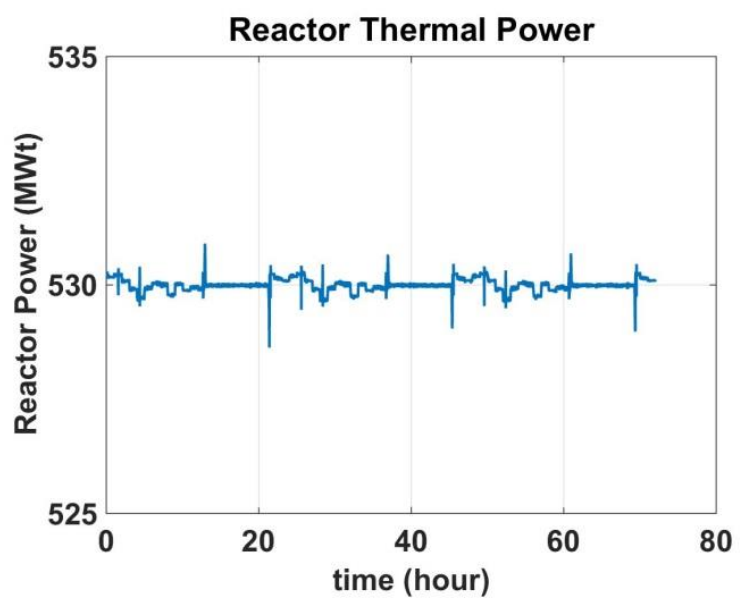

Figure 47: Reactor Power 


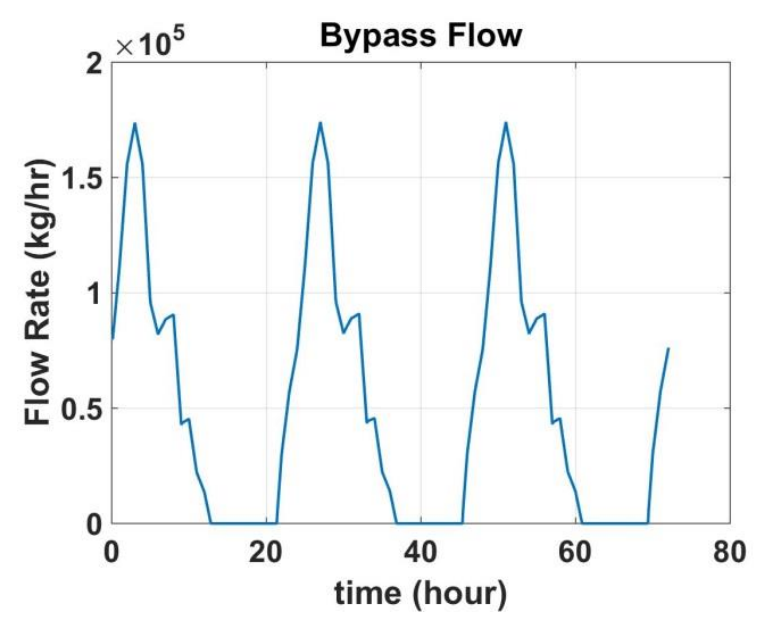

Figure 48: Auxiliary Bypass Flow

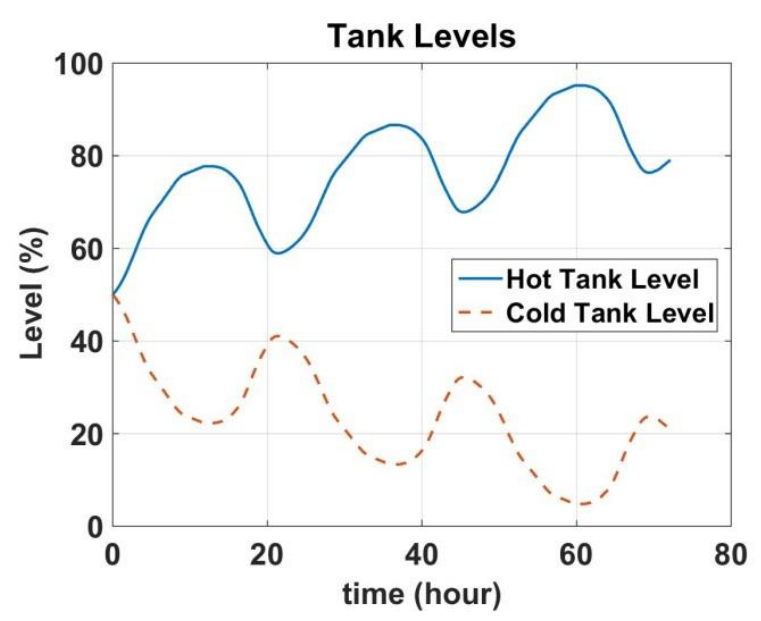

Figure 50: Hot and Cold Tank Level

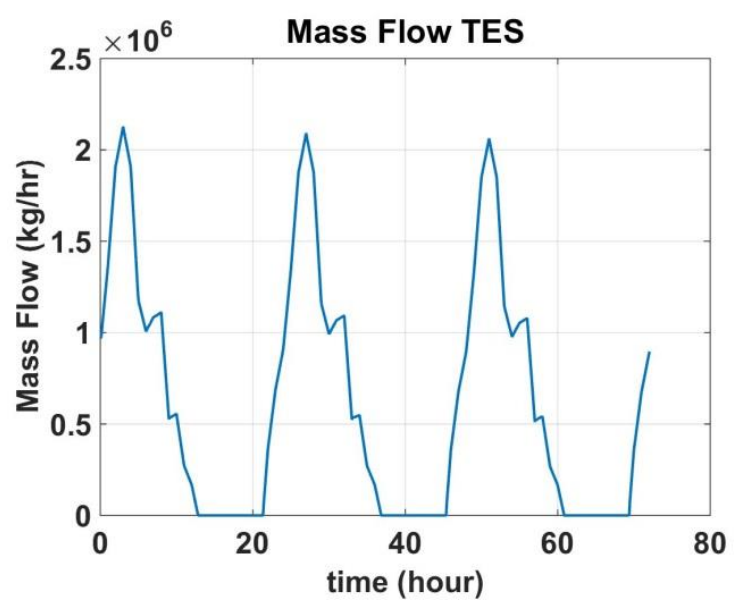

Figure 49: Flow of TES Fluid from Cold Tank to Hot Tank

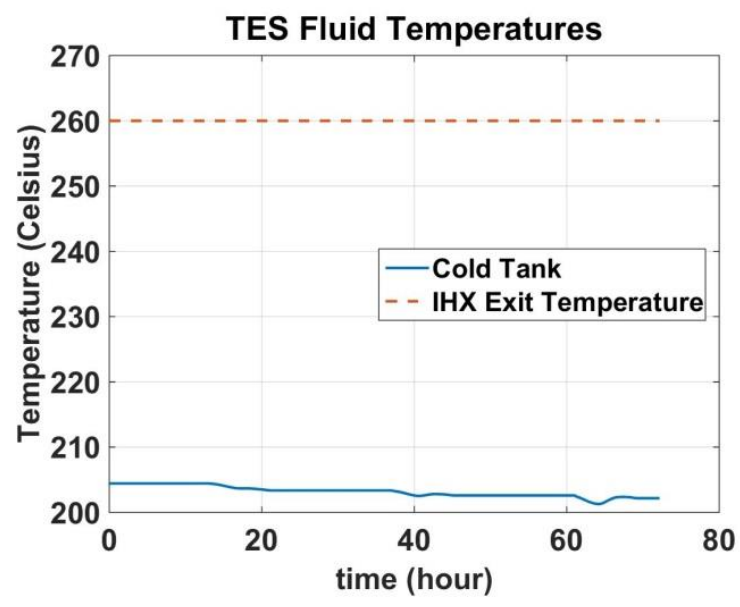

Figure 51: TES Fluid Temperature

\section{III.C.2. Three Summer Days with 15\% Solar Penetration (Third Day Cloudy)}

The second of the simulations is three summer days with $15 \%$ solar penetration where the third day is cloudy, thus limiting the solar output. Effects of having a cloudy day can be seen in Figures 52 through 57. As in the previous simulations, load is met while maintaining reactor thermal output as constant. Of particular interest is the effect of a cloudy day on tank levels, Figure 56 demonstrates this effect. During the first two sunny days, when nominal solar output is present, the hot tank goes from $50 \%$ full to about $70 \%$ full. However, the following 24 hours when only $10 \%$ nominal solar output is available the additional 
peaking requirements cause the hot tank to drop to $\sim 40 \%$ full. This weather variability necessitates additional charging on days when nominal renewable output is available.

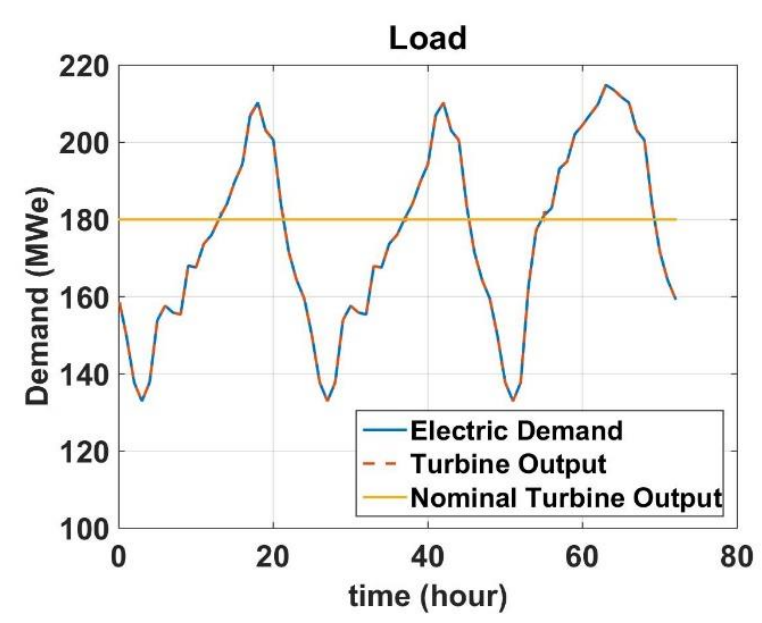

Figure 52: Turbine Output and Demand

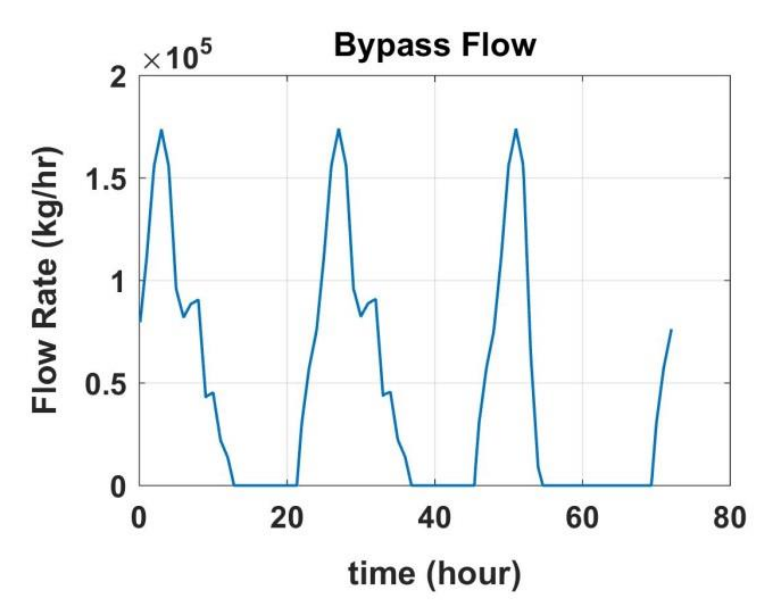

Figure 54: Auxiliary Bypass Flow

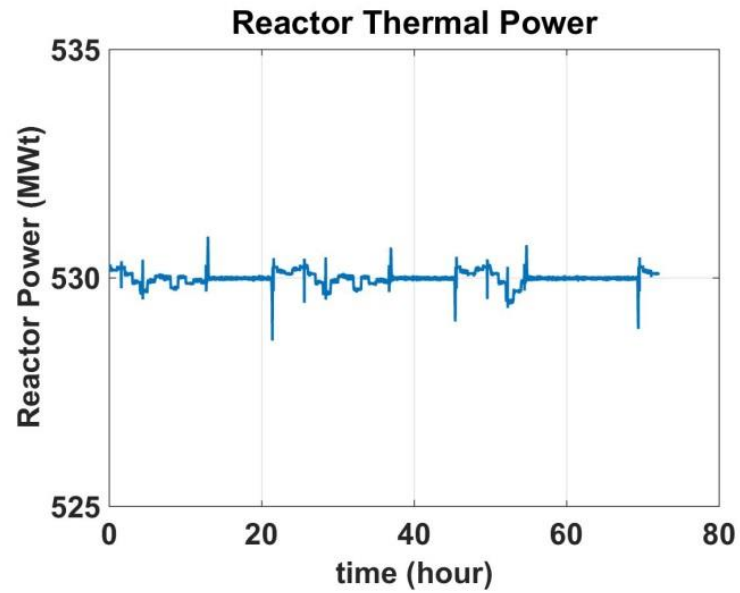

Figure 53: Reactor Power

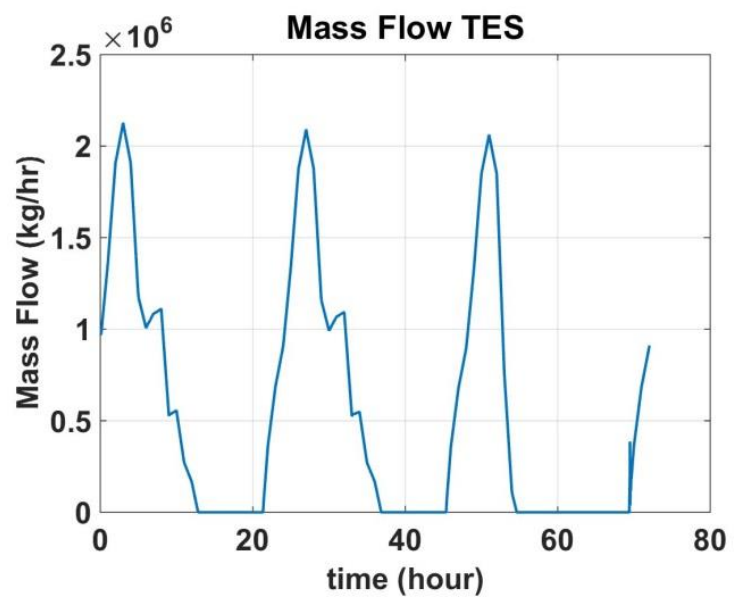

Figure 55: Flow of TES Fluid from Cold Tank to Hot Tank 


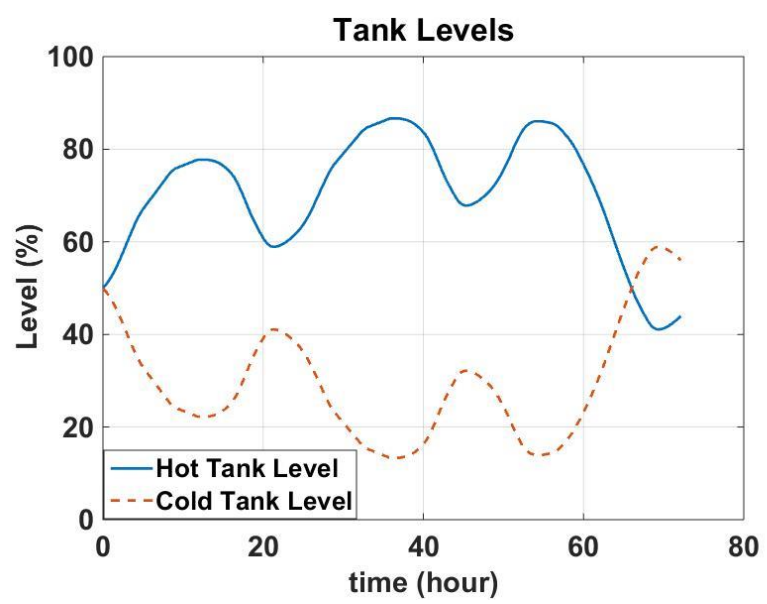

Figure 56: Hot Tank and Cold Tank Level

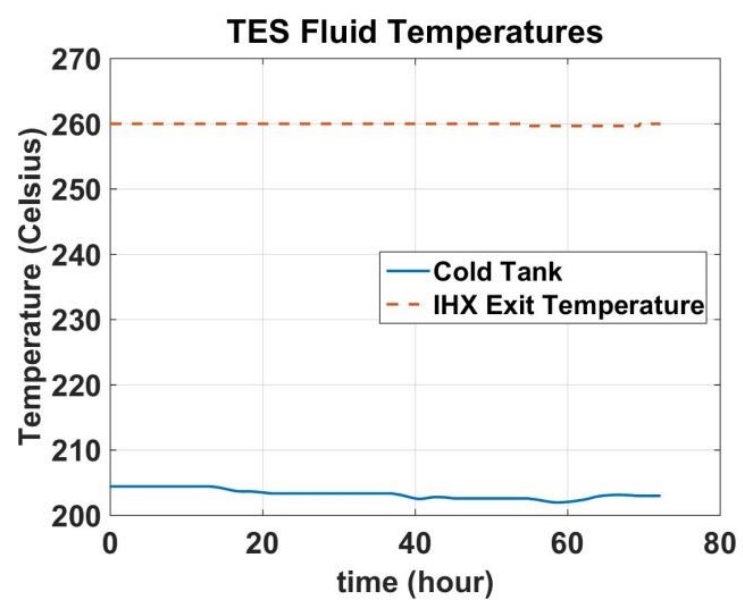

Figure 57: TES Fluid Temperature

\section{III.C.3. Three Winter Days with $15 \%$ solar penetration}

The final simulation is a three-day winter run with $15 \%$ solar penetration. The first and third days are sunny days with nominal solar output while the second day is rainy and overcast. Electric demand, turbine output and reactor thermal output are given in Figure 58 and Figure 59. As in previous simulations, load is met while reactor power is maintained at approximately 100\%. Mass flows through the TES system and tank levels are shown in Figure 60 through Figure 62. TES exit fluid temperatures are given in Figure 63.

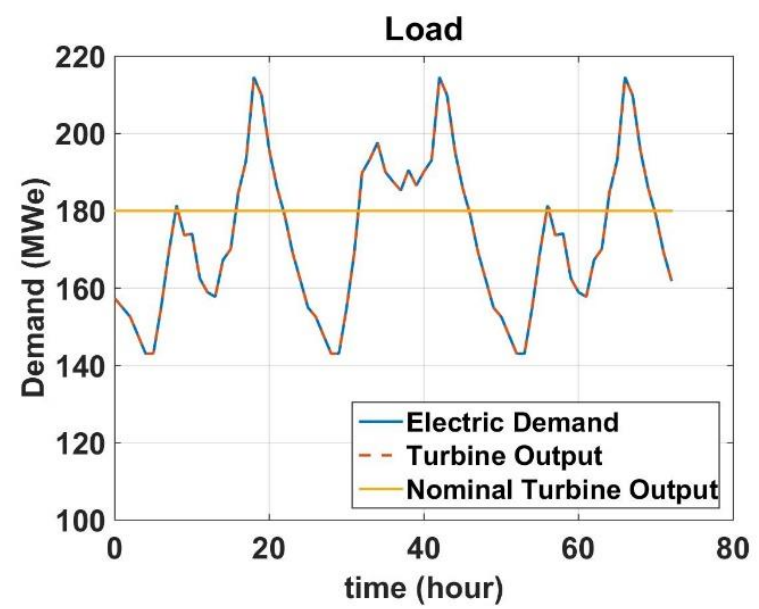

Figure 58: Turbine Output and Demand

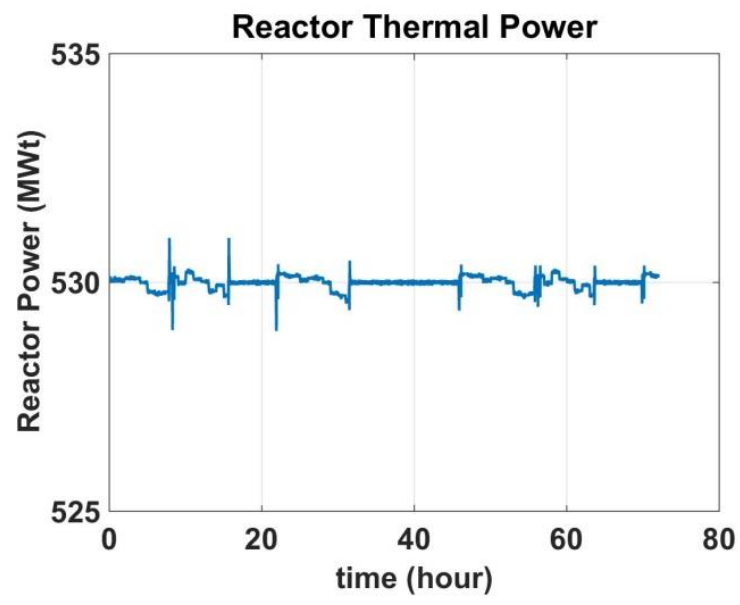

Figure 59: Reactor Power 


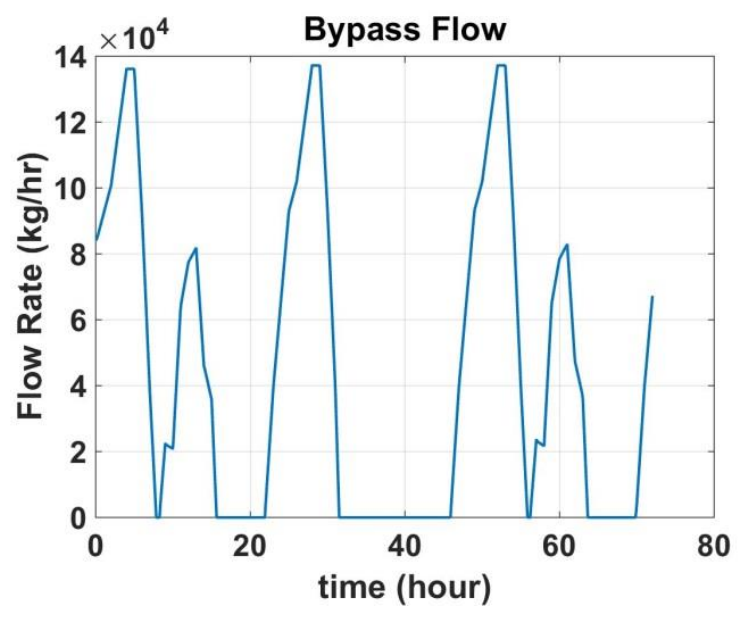

Figure 60: Auxiliary Bypass Flow

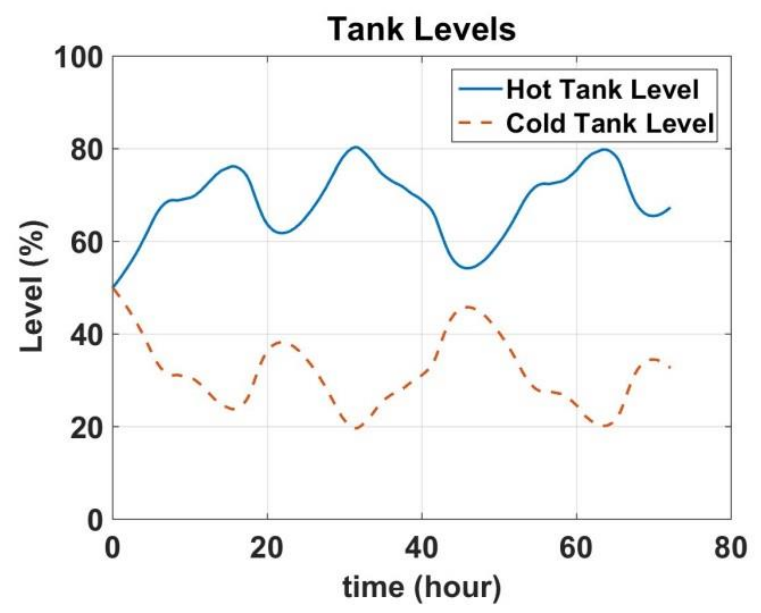

Figure 62: Hot Tank and Cold Tank Level

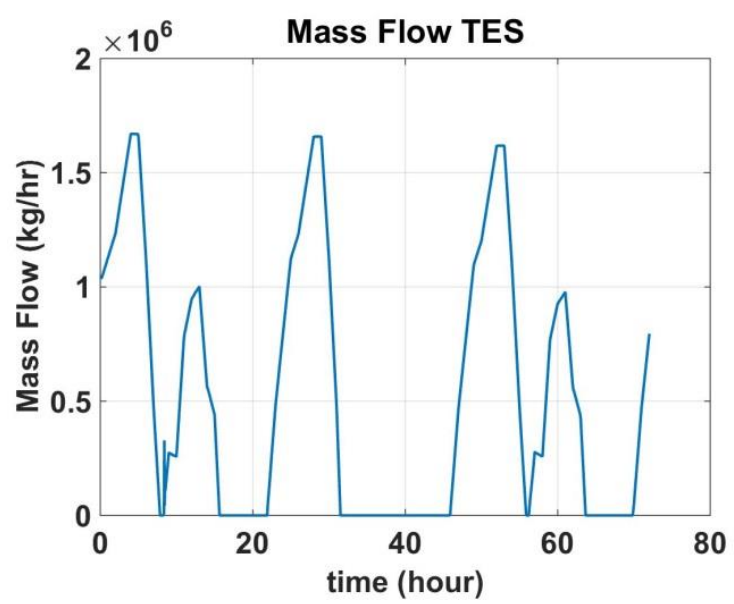

Figure 61: Flow of TES Fluid from Cold Tank to Hot Tank

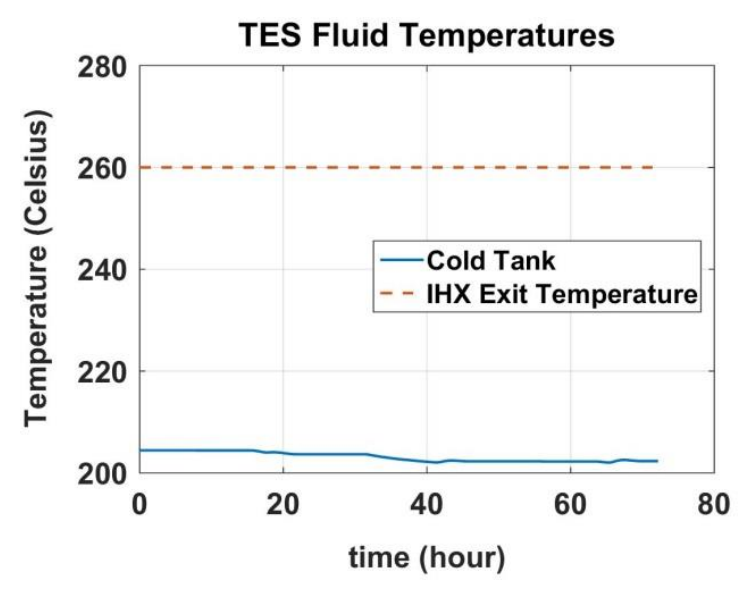

Figure 63: TES Fluid Temperature

\section{III.D. Steam Applications}

As opposed to using the TES system to supplement electric demand the system can alternatively be used for process steam applications. These applications include chilled water production and water desalination. Desalination can be accomplished through two main methods. One is Reverse Osmosis which just requires electrical input. Multi-stage flash desalination on the other hand requires a constant steam 
supply [27]. Chilled water production through the use of absorption chillers has been demonstrated in earlier work [20].

\section{III.D.1. Multi-Stage Flash Desalination}

Multi-stage flash desalination requires constant steam supply. The desalination process simulated is a 24 stage MSF system used to produce 7.2 MGD of product water [28]. To show the capabilities of the TES system when configured to produce process steam, a 24 hour desalination run was simulated starting at midnight of a typical summer day. While operating under these conditions, the TES system is charging and discharging simultaneously. The system is still able to meet electric load demands and maintain reactor power at approximately 100\%, as shown in Figure 64 and Figure 65. Bypass flow into the IHX is illustrated in Figure 66. Figure 67 shows the hot tank level is drastically reduced over the course of the 24 hour run while Figure 68 shows the reference temperature of the TES fluid entering the IHX is able to be maintained. Figure 69 shows that target steam flow is met throughout the run. For this 24 hour simulation a $226,535 \mathrm{~m}^{3}$ $\left(8,000,000 \mathrm{ft}^{3}\right)$ tank size is sufficient for a single day. However, to support this level of continuous desalination in the long term would require the tanks to be sized consistent with expected daily demands. These results show that a TES system operating in conjunction with MSF desalination is feasible. 


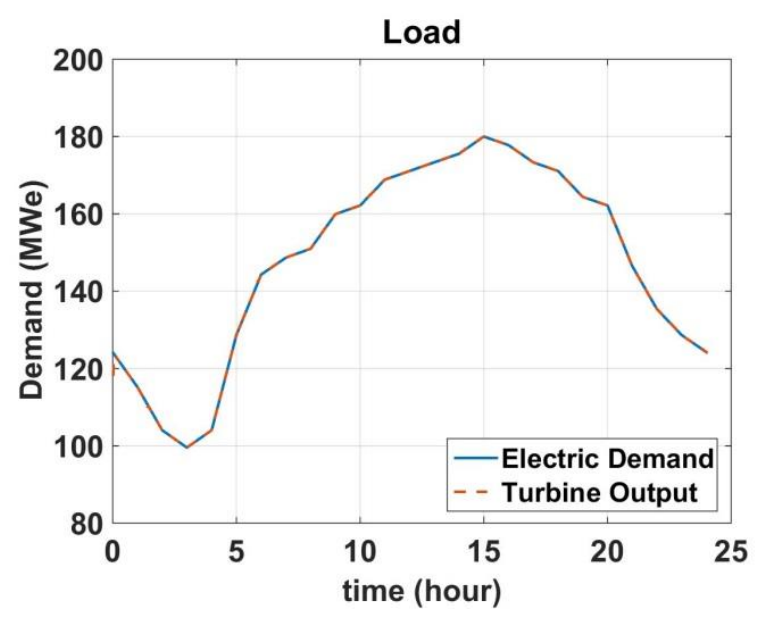

Figure 64: Turbine Output and Demand

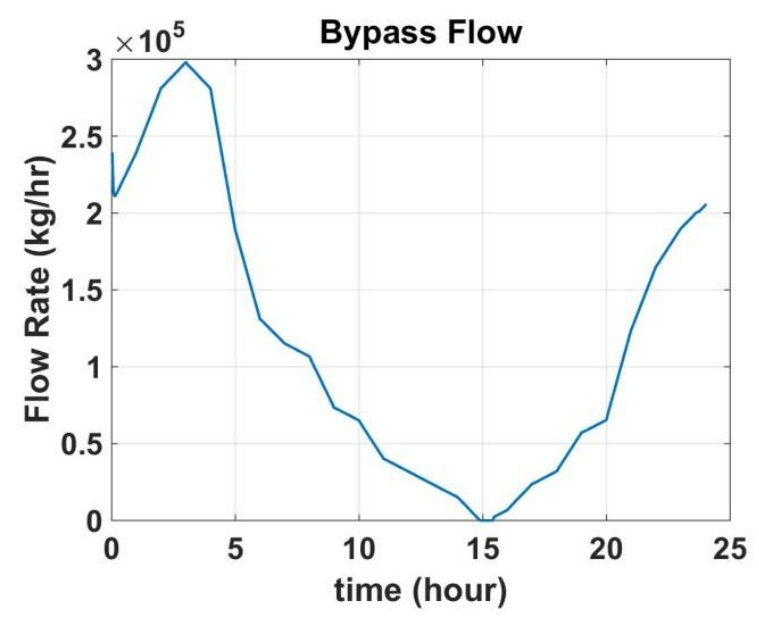

Figure 66: Auxiliary Bypass Flow

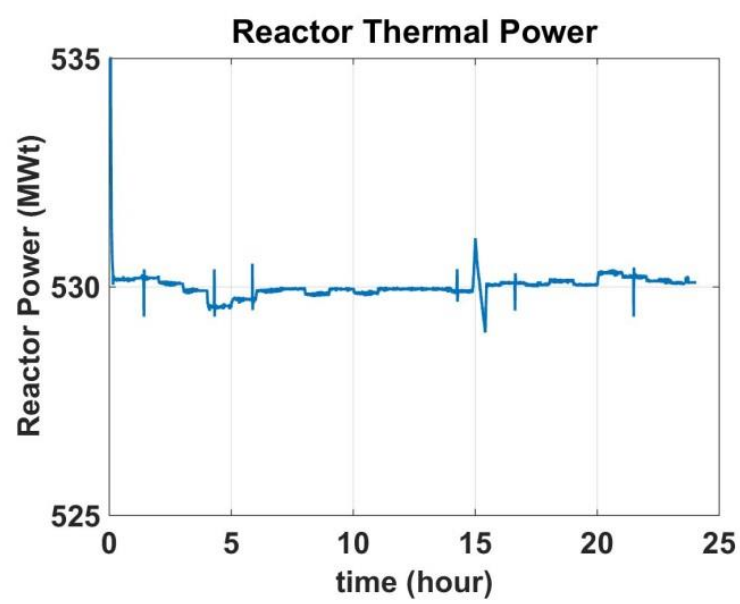

Figure 65: Reactor Power

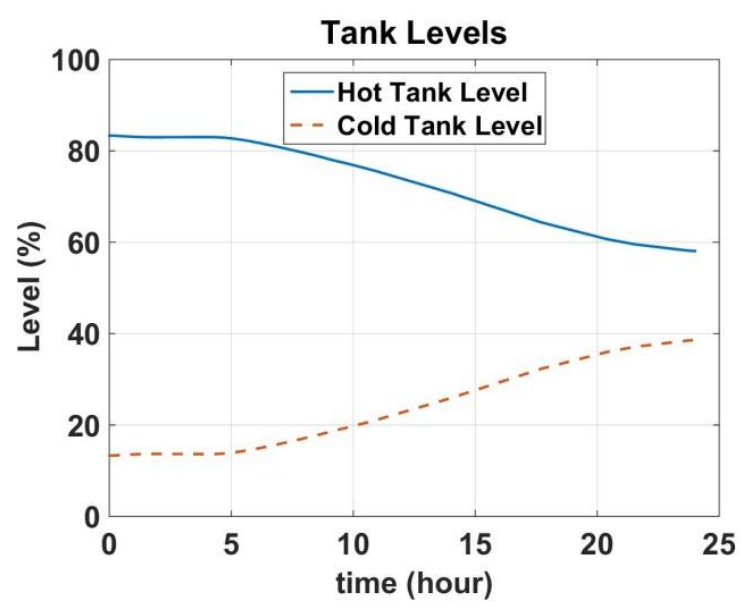

Figure 67: Hot Tank and Cold Tank Level 


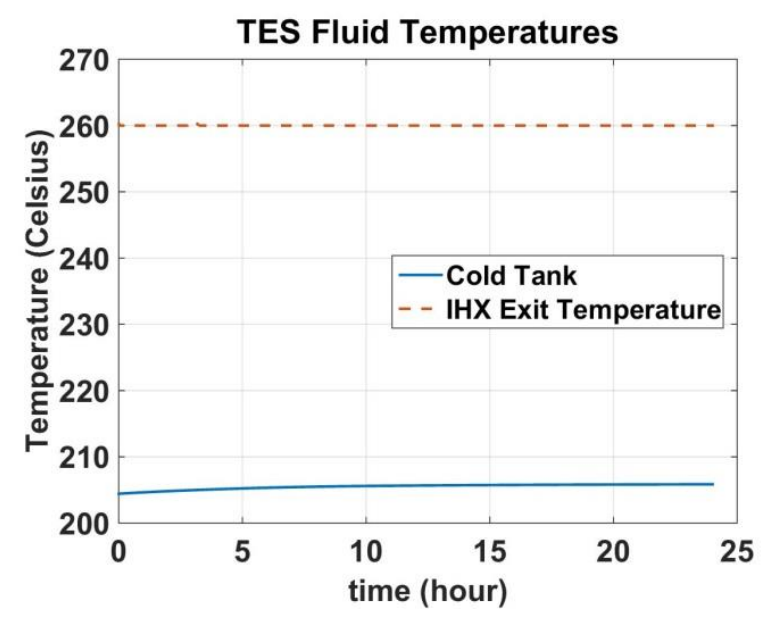

Figure 68: TES Fluid Temperature

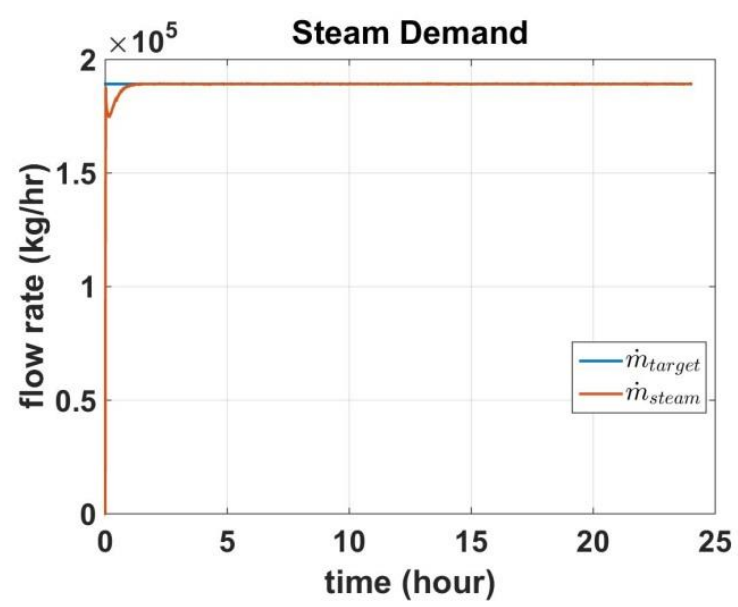

Figure 69: Ancillary Steam Demand and Flow

\section{Conclusions}

If SMRs are to be deployed in conjunction with intermittent power sources such as wind and solar, electric load variations can be significant. Current SMR designs allow for steam bypass off the pressure equalization header prior to the pressure control valves, thus providing approximately constant steam conditions ideal for sensible heat thermal energy storage systems. This study investigates the coupling of representative small modular reactor designs with a two-tank sensible heat thermal energy storage system to minimize power swings during periods of variable net electric load. During times of low electric demand, excess steam is bypassed to the TES system at a rate sufficient to maintain full reactor power. The thermal energy can be recovered later for either electricity production during periods of peak electric demand, or ancillary applications requiring steam such as multistage flash desalination.

With the implementation of these TES systems, decreased capacity factor and increased stresses on plant components associated with load follow operation can be minimized, improving economic return over the lifespan of the reactor. 


\section{Nomenclature}

$\begin{array}{ll}\alpha & \text { void fraction } \\ \text { A } & \text { area } \\ \text { ACV } & \text { auxiliary control valve } \\ \mathrm{c}_{\mathrm{p}} & \text { specific heat } \\ \text { FBV } & \text { feed bypass valve } \\ \text { FDCV } & \text { feed control valve } \\ \text { FCV } & \text { flow control valve } \\ \mathrm{H} & \text { height } \\ \mathrm{IHX} & \text { intermediate heat exchanger } \\ \mathrm{K} & \text { loss coefficient } \\ \mathrm{LPT} & \text { low pressure turbine } \\ \mathrm{M} & \text { mass } \\ \dot{\mathrm{m}} & \text { mass flow rate } \\ \mathrm{MWe} & \text { megawatts electric } \\ \mathrm{MWt} & \text { megawatts thermal } \\ \mathrm{OTSG} & \text { once through steam generator } \\ \mathrm{P} & \text { pressure } \\ \rho & \text { density } \\ \mathrm{PCV} & \text { pressure control valve } \\ \mathrm{PRV} & \text { pressure relief valve } \\ \Delta \mathrm{P} & \text { pressure drop } \\ \dot{\mathrm{q}} & \text { heat transfer rate per unit mass } \\ \dot{\mathrm{Q}} & \text { heat transfer rate } \\ \Delta \mathrm{t} & \text { change in time } \\ \mathrm{t} & \text { time } \\ \text { TBV } & \text { turbine bypass valve } \\ \text { TES } & \text { thermal energy storage } \\ \mathrm{u} & \text { internal energy } \\ \mathrm{v} & \text { velocity } \\ \mathrm{v} & \text { specific volume } \\ \mathrm{V} & \text { volume } \\ \dot{\mathrm{W}} & \text { power } \\ & \end{array}$

$\begin{array}{ll}\text { Subscripts } & \\ \text { cond } & \text { condenser } \\ \mathrm{CT} & \text { cold tank } \\ \mathrm{f} & \text { saturated liquid } \\ \mathrm{fg} & \text { range between saturated liquid and vapor } \\ \mathrm{g} & \text { saturated vapor } \\ \mathrm{HDR} & \text { header } \\ \mathrm{HT} & \text { hot tank } \\ \mathrm{IHX} & \text { intermediate heat exchanger } \\ \mathrm{j} & \text { node "j" } \\ \mathrm{l} & \text { liquid phase } \\ \text { Line } & \text { losses in lines } \\ \mathrm{p} & \text { pump } \\ \text { ref } & \text { reference } \\ \mathrm{r} & \text { relative }\end{array}$


SD

SG

steam dome

steam generator

$\mathrm{X}$

cross sectional area 


\section{References}

1. Appunn, K (2017, January 02). Why power prices turn negative. Retrieved December 4, 2017, from https://www.cleanenergywire.org/factsheets/why-power-prices-turn-negative.

2. P. Denholm, M. O'Connel, G. Brinkman and J. Jorgenson, "Overgeneration from solar energy in California: a field guide to the duck chart, National Renewable Energy Laboratory (NREL), Denver, CO, NREL/TP-6A20-65023," 2015.

3. F. Aydogan, G. Black, M. A. T. Black, and D. Solan, "Quantitative and Qualitative Comparison of Light Water and Advanced Small Modular Reactors," ASME J. Nucl. Eng. Radiat. Sci., 1, pp.0410011-14.

4. “Small Modular Reactors (SMRs)," http://www.energy.gov/ne/nuclear-reactor-technologies/smallmodular-nuclear-reactors (2017).

5. D. Ingersoll, C. Colbert, Z. Houghton, R. Snuggerud, J. Gaston, and M. EMPEY. "Can Nuclear Power and Renewables Be Friends?" Proceedings of ICAPP (2015): 3129-3137. Print.

6. Advances in Small Modular Reactor Technology Developments; A supplement to IAEA Advanced Reactors Information System (ARIS), IAEA (2014)

7. S. M. Bragg-Sitton, R. Boardman, C. Rabiti, J. S. Kim, M. McKellar, P. Sabharwall, J. Chen, M. S. Cetiner, T. J. Harrison and L. A. Qualls, "Nuclear-Renewable Hybrid Energy Systems: 2016 Technology development program plan, Idaho National Laboratory (INL), Idaho Falls, ID, INL/EXT16-38165," 2016.

8. H. Shen, "Advanced Feedwater Control for Next Generation Nuclear Power Systems," PhD Thesis, Nuclear Engineering Department, North Carolina State University, (2006).

9. Alan S. Rominger and J. Michael Doster , "Fast Valving for Small and Medium Sized Reactors", Proceedings of the $7^{\text {th }}$ International Topical Meeting on Nuclear Plant Instrumentation, Control and Human Machine Interface Technologies (NPIC\&HMIT 2010) Las Vegas, Nevada, November 2010

10. Alan S. Rominger and J. Michael Doster , "Benefits of Small Modular Reactors for Challenging Electric Grid Operation", Proceedings of the $8^{\text {th }}$ International Topical Meeting on Nuclear Plant Instrumentation, Control and Human Machine Interface Technologies (NPIC\&HMIT 2012) San Diego, CA, July, 2012

11. Andrew J. Petrarca and J. Michael Doster, "Low Power Feedwater Control in Helical Steam Generators", Proceedings of the $8^{\text {th }}$ International Topical Meeting on Nuclear Plant Instrumentation, Control and Human Machine Interface Technologies (NPIC\&HMIT 2012) San Diego, CA, July, 2012

12. K. Powell, T. Edgar. "Modeling and control of a solar thermal power plant with thermal energy storage". Chemical Engineering Science. 138-145, 71 (2012).

13. Konor Frick, Corey T. Misenheimer, J. Michael Doster, Stephen D. Terry \& Shannon Bragg-Sitton (2018) Thermal Energy Storage Configurations for Small Modular Reactor Load Shedding, Nuclear Technology, 202:1, 53-70, DOI: 10.1080/00295450.2017.1420945 
14. Sohal, M. S., Ebner, M. A., Sabharwall, P., \& Sharpe, P. (March 2010). Engineering Database of Liquid Salt Thermophysical and Thermochemical Properties. Idaho National Laboratory. INL/Ext-1018297

15. Therminol-66; MSDS 150000093438 [Online]; Eastman Chemical Company: 200 South Wilcox Drive, Kingsport, TN 37660-5280, April 11,2017. http://ws.eastman.com/ProductCatalogApps/PageControllers/MSDS_PC.aspx?Product $=71093438$ (accessed Dec 04, 2017).

16. OpenStax College, Chemistry OpenStax College. 11 March 2015.

$<$ http://cnx.org/content/col11760/latest/>.

17. Solutia: Applied Chemistry, Creative Solutions, Therminol 66: High Performance Highly Stable Heat Transfer Fluid.

18. Solutia: Applied Chemistry, Creative Solutions, Therminol 68: Highly Stable Low Viscosity Heat Transfer Fluid.

19. Solutia, Therminol 75: Synthetic, Aromatic, High-temperature Heat Transfer Fluid.

20. C. Misenheimer, Modeling Chilled-Water Storage System Components for Coupling to a Small Modular Reactor in a Nuclear Hybrid Energy System, PhD Dissertation, Department of Mechanical and Aerospace Engineering, North Carolina State University, 2017.

21. K. Frick, Modeling and Design of a Sensible Heat Thermal Energy Storage System for Small Modular Reactors, PhD Dissertation, Department of Nuclear Engineering, North Carolina State University, 2018.

22. K. Atkinson, An Introduction to Numerical Analysis, J Wiley and Sons, 1989, pg 91.

23. "Renewable Energy and Electricity," 20 June 2016. [Online]. Available: http://www.worldnuclear.org/information-library/energy-and-the-environment/renewable-energy-andelectricity.aspx. [Accessed 08 July 2016].

24. Search Import Export Data of India. (n.d.). Retrieved December 04, 2017, from https://www.zauba.com/import-therminol 66-hs-code.html

25. U.S. Energy Information Administration - EIA - Independent Statistics and Analysis. (n.d.). Retrieved December 04, 2017, from https://www.eia.gov/beta/realtime_grid/\#/summary/demand?end=20160725 \&start $=20160625$ (ions $=00 \mathrm{~g}$

26. Richardson, L. (2017, May 09). Do Solar Panels Work at Night or On Cloudy Days? | EnergySage. Retrieved December 08, 2017, from https://news.energysage.com/solar-panels-work-night-cloudyday/

27. M. A. Darwish and N. M. Al-Najem, "Energy consumption by multi-stage flash and reverse osmosis desalters," Applied Thermal Engineering, pp. 399-416, 2000.

28. El-Dessouky, H. T., \& Ettouney, H. M. (2002). Fundamentals of Salt Water Desalination. Amsterdam: Elsevier Science. 